\title{
Movement Rate Is Encoded and Influenced by Widespread, Coherent Activity of Cerebellar Molecular Layer Interneurons
}

\author{
Michael A. Gaffield and Jason M. Christie \\ Max Planck Florida Institute for Neuroscience, Jupiter, Florida 33458
}

Inhibition from molecular layer interneurons (MLIs) is thought to play an important role in cerebellar function by sharpening the precision of Purkinje cell spike output. Yet the coding features of MLIs during behavior are poorly understood. To study MLI activity, we used in vivo $\mathrm{Ca}^{2+}$ imaging in head-fixed mice during the performance of a rhythmic motor behavior, licking during water consumption. MLIs were robustly active during lick-related movement across a lobule-specific region of the cerebellum showing high temporal correspondence within their population. Average MLI Ca ${ }^{2+}$ activity strongly correlated with movement rate but not to the intentional, or unexpected, adjustment of lick position or to sensory feedback that varied with task condition. Chemogenetic suppression of MLI output reduced lick rate and altered tongue movements, indicating that activity of these interneurons not only encodes temporal aspects of movement kinematics but also influences motor outcome pointing to an integral role in online control of rhythmic behavior.

Key words: cerebellum; inhibition; molecular layer interneuron

\section{Significance Statement}

The cerebellum helps fine-tune coordinated motor actions via signaling from projection neurons called Purkinje cells. Molecular layer interneurons (MLIs) provide powerful inhibition onto Purkinje cells, but little is understood about how this inhibitory circuit is engaged during behavior or what type of information is transmitted through these neurons. Our work establishes that MLIs in the lateral cerebellum are broadly activated during movement with calcium activity corresponding to movement rate. We also show that suppression of MLI output slows and disorganizes the precise movement pattern. Therefore, MLIs are an important circuit element in the cerebellum allowing for accurate motor control.

\section{Introduction}

Movement encompasses a wide range of behavior from smooth, targeted actions such as reaching motions to rhythmic control of locomotion. The cerebellum plays a central role in ensuring that all types of movement are well timed and highly coordinated (Ito, 2012). During active behavior, Purkinje cells modulate their fir-

Received Feb. 24, 2017; revised March 31, 2017; accepted April 2, 2017.

Author contributions: M.A.G. and J.M.C. designed research; M.A.G. performed research; M.A.G. analyzed data; M.A.G. and J.M.C. wrote the paper.

This work was supported by National Institutes of Health Grant NS083894 (J.M.C) as well as the Max Planck Society (Max Planck Gesellschaft) and the Max Planck Florida Institute for Neuroscience (MPFI). We thank Samantha Amat for technical assistance and laboratory support, and all the other members of the Christie Lab for their helpful discussions and comments during the completion of this project. Our work was aided by the contributions of the MPFI Animal Resource Center, the MPFI Light Microscopy Core, the MPFI Molecular Core, and the MPFI Mechanical Workshop. We are indebted to Haruhiko Bito for the use of RCaMP2 and the GENIE Program at the Janelia Research Campus for generously making their $\mathrm{Ca}^{2+}$ sensors freely available, including the GCaMP6f that was used in this project.

The authors declare no competing financial interests.

Correspondence should be addressed to Jason M. Christie, Max Planck Florida Institute for Neuroscience, Jupiter,

FL 33458.E-mail: jason.christie@mpfi.org.

DOI:10.1523/JNEUROSCI.0534-17.2017

Copyright $\odot 2017$ the authors $\quad 0270-6474 / 17 / 374751-15 \$ 15.00 / 0$ ing rate in correlation with movement (Thach, 1968; Lisberger and Fuchs, 1978) to influence downstream motor centers via their inhibitory output (Lee et al., 2015). In the cerebellar system, the mossy fiber pathway conveys sensorimotor information to the cortex, exciting granule cells that, in turn, make excitatory synapses onto both Purkinje cells and inhibitory molecular layer interneurons (MLIs). Due to the connectivity of MLIs onto Purkinje cells, granule cells both directly excite Purkinje cells and also inhibit them through feedforward and lateral inhibition (Eccles et al., 1967; Mittmann et al., 2005; Dizon and Khodakhah, 2011). Thus, the representation of sensorimotor context conveyed through Purkinje cell simple spiking is determined not only on by granule cell-mediated excitation, but also molecular layer inhibition. The net effect of inhibition will depend on how MLIs are recruited during movement. Yet the sensorimotor coding properties of MLIs and their net influence on motor behavior remain poorly understood.

Computationally, feedforward inhibition from MLIs sharpens the integration window for granule cell excitation of Purkinje cells (Mittmann et al., 2005), increasing the precision of a linear 
rate coding algorithm (Walter and Khodakhah, 2006; Walter et al., 2009) that can accurately represent movement kinematics during behavior (Chen et al., 2016). Previous observations indicate that MLI activity increases during motor output (Ozden et al., 2012; ten Brinke et al., 2015; Jelitai et al., 2016). Moreover, optogenetic activation of MLIs can drive precisely timed movements through inhibition of Purkinje cells during quiescence (Heiney et al., 2014), and optogenetic inhibition of MLIs often slows or stops movement (Jelitai et al., 2016). Thus, MLIs may play a commanding role in not only integrating information to predict features of impending motor action but also influence the online control of cerebellar output to affect behavior, ideas central to cerebellar function (Medina, 2011). Whether MLIs implement a coding strategy similar to Purkinje cells, tuned to salient features of movement, has yet to be established. As it has been proposed that MLIs and Purkinje cells are excited by largely nonoverlapping populations of granule cells (Ekerot and Jörntell, 2001; Jörntell and Ekerot, 2002; Barmack and Yakhnitsa, 2008), it remains possible sensorimotor information is differentially relayed and processed by these two neuron types.

In this report, we analyzed the coding properties of MLIs during the performance of a rhythmic motor task, licking during water consumption. Measuring their $\mathrm{Ca}^{2+}$ activity, we found that lick rate, but not tongue or mouth position, was accurately encoded in the average response of MLIs within a lobule-specific region of the lateral hemisphere. This kinematic feature was represented in a near-uniform manner in the MLI population within that region, suggestive of nonspecialized, global inhibition within the molecular layer. Chemogenetic suppression of their output reduced lick rate and increased the variability of tongue trajectories suggesting that the computational function of these interneurons plays an instrumental role in determining cerebellar-dependent refinement of online motor control.

\section{Materials and Methods}

Animal and surgical procedures. All procedures were performed on animals under protocols approved by the Institutional Animal Care and Use Committee at the Max Planck Florida Institute for Neuroscience (MPFI). Heterozygous adult $c-k i t^{I R E S-C r e}$ mice (S. Amat, M. Rowan, M. Gaffield, A. Bonnan, C. Kikuchi, H. Taniguchi, and J. Christie, unpublished observations) were used for all experiments ( $>10$ weeks of age; 16 female, 11 male). Sample size estimates were computed for experiments in Figure 8 only. Calculations determined the number of animals required to reach a significant result $(p<0.05)$ with $90 \%$ power. Cranial windows for in vivo brain imaging were prepared under isoflurane anesthesia as described previously (Gaffield et al., 2016). Briefly, the skull was exposed through surgical excision of the scalp, and then a custom-engineered stainless-steel head post was attached, centered on the midline of the cranium, using dental cement onto dry bone. A small craniotomy $(\sim 2$ $\mathrm{mm}$ square) was cut over the lateral cerebellum using a scalpel without disturbing the underlying dura mater. For experiments using hM4Di, smaller craniotomies were used, just large enough for micropipettes to easily fit through, and were cut over Crus II bilaterally in each hemisphere.

Adeno-associated virus (AAV) was injected into the brain using beveled glass micropipettes. Viruses included either AAV1.CAG.Flex.GCaMP6f. WPRE.SV40 (Figs. 1, 5), AAV1.CAG.DIO.RCaMP2.WPRE.SV40 (Figs. 2-7), AAV5.hSyn.DIO.hM4Di.mCherry (Fig. 8), or AAV1.CAG.Flex.ChR2. HA.2a.hM4Di (Fig. 8). In a subset of experiments, sparse labeling of MLIs $\left(\sim 1\right.$ cell per $[100 \mu \mathrm{m}]^{2}$ or $<10$ labeled MLIs in the field of view) was achieved by the leaky expression of a FlpO-dependent GCaMP6f-containing virus (AAV1.CAG.FRT.GCaMP6f.FRT.WPRE.bGH) in $c-k i t^{I R E S-C r e}$ mice. This resulted in well-isolated MLIs without neuropil-associated fluorescence signals. All viruses were packaged at the University of Pennsylvania Vector Core Facility except for AAV1.CAG.FRT.GCaMP6f.FRT.WPRE.bGH, packaged at the University of North Carolina Vector Core Facility, and AAV1.CAG.Flex.ChR2.HA.2a.hM4Di, which was custom packaged at ViGene Biosciences. D-mannitol $(750 \mathrm{mg} / \mathrm{kg}$ ) was delivered by intraperitoneal injection about $1 \mathrm{~h}$ before surgery to improve viral spread except for hM4Di-containing viruses where we attempted to limit transduction to Crus II. The micropipettes were inserted $\sim 100-200 \mu \mathrm{m}$ below the dura, and virus was injected $(200-400 \mathrm{nl} ; \sim 25 \mathrm{nl} / \mathrm{min})$ at several locations within the region of the craniotomy. For hM4Di-containing viruses, a smaller volume $(\sim 150 \mathrm{nl})$ was injected at one location per hemisphere. After ejection, the pipette was kept in position for 2-3 min before retraction. Last, for imaging experiments, a small glass coverslip was cemented in place providing transparent access to the exposed region of the lateral cerebellar cortex (Holtmaat et al., 2009).

Behavior task. After surgical recovery, mice were trained to consume water from a lick port under head fixation. To motivate task participation, mice were maintained on a water-restricted diet for 10 or more days before the start of an experiment (water restriction began $>5 \mathrm{~d}$ after surgery). During water restriction, mice received $1 \mathrm{ml}$ of water per day, and a running wheel was added to each cage for enrichment. Daily weight and health monitoring confirmed that mice quickly adapted to reduced water intake and were not in distress.

For our experimental recordings and manipulations, mice were manually placed in a purpose-built apparatus by attaching the surgically implanted head post to a rigid fixture. The apparatus, fully enclosed to restrict light and sound, included a lick port with a built-in lick detection circuit (Slotnick, 2009). To familiarize mice with use of the lick port, the first dispensed aliquots of water were provided in the immediate vicinity of the animal's mouth. On subsequent trials, the port was moved slightly away from the face, and free access to water was provided until the animal was sate. Once the mice would lick on their own volition, they transitioned to a cued licking task. Most mice required a single $15 \mathrm{~min}$ training session (accumulating $\sim 500-2500$ licks) before advancement. During the cued task, a tone $(6 \mathrm{kHz}, 200 \mathrm{~ms})$ was presented, and if the mouse licked, a water reward was dispended in one of three volumes $(0,4$, or $8 \mu \mathrm{l}$ ), each delivered in a pseudorandomized manner. Water was not dispensed if the mouse did not lick following the tone. Visual inspection of a subset of trials with high-speed videography revealed that mice required three to four licks to fully consume small volumes of water from the lick port $(\leq 8 \mu \mathrm{l})$. Analysis of 1052 cued bouts showed that mice $(n=$ 5) licked at least three times in $97.8 \%$ of trials and at least four times in $99.2 \%$ of trials. Therefore, we deemed it unlikely that water remained on the port after cessation of licking precluding the need for active removal of liquid before the next cued trial. Mice typically achieved mastery of the cued task within a few days $(\sim 150$ trials per day) as determined by evoked licks on nearly all trials ( $>100$ per session) and withholding of licking between trials. In some experiments, the lick port was rapidly lowered out of reach before a trial using a small servo motor, triggered with a TTL signal. The servo arm and lick port moved back to the normal position after the end of the trial. The behavior apparatus was controlled with a real-time Linux machine running BControl software (C. Brody lab, Princeton University, Princeton, NJ) communicating over Ethernet with a second computer allowing user interfacing, as described previously (Gaffield et al., 2016).

For experiments in mice expressing the engineered receptor hM4Di, animals received an intraperitoneal injection of clozapine- $N$-oxide (CNO) $45 \mathrm{~min}$ before start of the task $(5 \mathrm{mg} / \mathrm{kg}$; Tocris Bioscience; stock solutions were made by dissolving CNO in DMSO to $50 \mathrm{~mm}$ ). The task involved providing water periodically $(4 \mu \mathrm{l} ; 0.8 \mathrm{~Hz})$ without a tone, and continued as long as the mouse participated by licking. Control measurements in the absence of $\mathrm{CNO}$ were made from the same mice on alternate days ( $\geq 24$ h between sessions)

We used high-speed videography to monitor oral-facial movements during water consumption. This included an EoSens CL MC1362 (CAMMC1362) camera from Mikrotron with a $0.25 \times$ telecentric lens from Edmund Optics (catalog \#55-349) for focusing. The camera interfaced with a computer using a PCIe-1473R frame grabber and PCIe-1429 camera link board (National Instruments, parts 782849-01 and 78086901). Images were collected at $1000 \mathrm{~Hz}$, using custom-written software in LabVIEW (National Instruments). The oral-facial region was back- 
illuminated with a $940 \mathrm{~nm}$ LED from Thorlabs (part M940L3) to create a high-contrast image for processing and quantification.

Fluorescence imaging. Our custom-built laser-scanning microscope was based on an modular in vivo multiphoton microscopy system platform (D. Flickinger, Howard Hughes Medical Institute, Ashburn, VA) that included a Zyla 5.5 sCMOS camera (Andor Technology) for widefield fluorescence imaging. The camera was connected via camera link to a computer running Solis software (Andor Technology). Images were collected at $30 \mathrm{~Hz}(\sim 330 \mu \mathrm{m}$ in each dimension). Fluorescence resulted from illumination with a $470 \mathrm{~nm}$ LED (part M470L3, Thorlabs) using a $10 \times, 0.25$ numerical aperture (NA) air objective (Olympus) for focusing and collection. Our imaging system for two-photon microscopy included a resonant scanning mirror (Cambridge Technology) allowing for high frame rate imaging $(30 \mathrm{~Hz})$ acquired continuously using ScanImage 2015 software (Vidrio Technologies) as described previously (Gaffield et al., 2016). GCaMP6f was excited at $900 \mathrm{~nm}$ using a tunable Ti: Sapphire laser (Chameleon Vision S laser; Coherent). In some cases RCaMP2 was excited using 980-1000 nm from the Vision S, but in most cases RCaMP2 excitation resulted from $1070 \mathrm{~nm}$ light out of a Fidelity-2 fiber laser (Coherent). Laser power out of the objective (16×, $0.8 \mathrm{NA}$; Olympus) was typically $<50 \mathrm{~mW}$ for GCaMP6f and $<80 \mathrm{~mW}$ for RCaMP2.

For fixed tissue analysis, animals were perfused with paraformaldehyde through the aorta under deep ketamine $(100 \mathrm{mg} / \mathrm{kg})$ and xylazine $(10 \mathrm{mg} / \mathrm{kg})$ anesthesia. The cerebellum was dissected from the skull, and the lateral regions sectioned using a microtome. Expression of hM4Di was confirmed (depending on the virus) by either direct imaging of mCherry or by incubating the tissue with an anti-HA antibody (catalog \#ab9110, Abcam), followed by an Alexa 633 secondary antibody (Thermo Fisher Scientific). After mounting on glass coverslips, images were collected on a confocal microscope (LSM 780 Axio Imager 2; Zeiss) using $488 \mathrm{~nm}$ excitation and 493-598 nm emission for GCaMP6f, $561 \mathrm{~nm}$ excitation and 578-696 nm emission for mCherry, or $633 \mathrm{~nm}$ excitation and 638-747 nm emission for Alexa 633.

Image analysis. All image analysis used custom routines written in MATLAB (MathWorks). Epifluorescence difference images were calculated by subtracting the average of the first 50 frames after licking commenced from the average of the previous 50 frames when no licking occurred. Alignment of images from different mice was achieved by using the Crus I/II boundary as a marker. Imaging field locations across mice were also related by using the three-dimensional coordinates of the objective stage motor and the coordinates of the cranial window placement. Peak $\Delta F$ comparisons for Crus I and Crus II were calculated using similarly sized ROIs for each lobule that excluded prominent blood vessels. Figure $1 E$ shows time correlations between each pixel in the image and the average response for the regions identified as lick dependent (every pixel in Fig. $1 D$ above the pixel-by-pixel intensity SD) during a $30 \mathrm{~s}$ period mixed with licking and nonlicking epochs. For imaging data collected using two-photon microscopy, all frames were first rigidly aligned using a least squares algorithm. Next, all ROIs were selected by hand using reference images of 1000 frame averages. Only MLIs with clearly demarcated cell bodies were used in the analysis. Due to the curvature of lobules Crus I and II under the cranial window, image planes were not parallel to the brain surface. Instead, optical sections often spanned a majority of the depth of the molecular layer that included proximal and distal MLIs (presumptive stellate and basket cells, respectively). ROI locations were based on the centroid positions of ROI masks. All correlations were calculated using a standard cross-correlation function. Derivatives of the lick rate and fluorescence were calculated by taking the difference between each time point. In cases where either all data or individual trials were scrambled, we randomized the order of a vector containing the data.

Instantaneous lick rate was calculated during a bout using a moving series of three licks with the equation $\mathrm{LR}_{2}=3 /\left(\mathrm{T}_{3}-\mathrm{T}_{1}\right)$, where $\mathrm{LR}_{2}$ is the lick rate at the second lick, and $\mathrm{T}_{1}$ and $\mathrm{T}_{3}$ are the times of the first and third licks in the series, respectively. For movement rate measurements during chemogenetic manipulations, lick rate is presented as the inverse of the lick interval. The time of lick port contact was used to identify a lick for most rate-based movement analyses. In trials where the lick port moved, high-speed videography was used to calculate lick rate based on the time between subsequent tongue appearances. Typically, mice completely closed their mouths at the completion of a lick, demarcating the end of an individual lick. However, we counted as multiple licks cases where the tongue retracted, but then protracted again before completely entering the mouth. This method of counting more accurately matched lick events discriminated by lick port contact where such tongue movements would be registered as two separate contact events. The normalized lick rate was calculated by multiplying lick rate and lick probability, allowing us to average lick rates across trials with varying lick bout durations. Since licks occurred at slightly different times, lick probability was calculated by sorting licks in time, based on the relation of the first lick to the opening of the water valve. Then we put each successive rhythmic lick into the subsequent bin. The time of each bin could then be calculated from the average lick rate. We normalized each peak value (either $\Delta F / F$ or lick rate) to the average session value to compare these two measurements across different sessions, each with a slightly different distribution.

High-speed videography was used to quantify lick dynamics. Individual licking bouts were separated based on ROIs drawn in the upper or lower part of the lick port along with a region near the mouth to identify frames that included licking movements. The frames were then classified based on when the tongue was in each ROI. The ratio of the percentage of lower lick frames to the percentage of upper lick frames then allowed us to sort images containing a lick series. Heat maps of tongue positions were simply average tongue positions of all frames collected when the tongue was visible (based on intensity changes within an ROI in the tongue's path). The average tongue position was calculated from the peak ridge in these images, while the lower jaw was based on the position of the same gradient line across each image. In some cases, specific tongue trajectories were drawn by identifying the location of the tip of the tongue, as determined by the apex of the curve at the tip. For most cases, including for tongue velocity measurements, tongue trajectories were calculated by an algorithm that first inverted the image and then subtracted the average of all frames from each individual frame. Since the tongue was back-illuminated, this created a difference image that included objects that moved in each frame. Morphology was then used to isolate the tongue from the rest of the mouth. Once the tongue was isolated, the position was determined from the center of mass of the tongue (or centroid), and then velocity was calculated based on changes in position between successive frames. To partition epochs of mouth opening and closure, we used a machine learning algorithm. First, a subset of images (1000 frames) containing frames where the mouth was either open or closed was selected by visual inspection. Then 300 features were identified algorithmically using MATLAB's bag of features that helped classify the images. Next, a quadratic support vector machine was used to build a model, based on those 300 features, that predicted the classification of unsorted frames. A strong agreement between the resulting lick intervals and the lick port contact intervals confirmed the quality of the sorting.

For estimating the expected $\mathrm{MLI} \mathrm{Ca}^{2+}$ response from the underlying lick pattern, we used a model that divided a licking bout into three epochs: the initial three licks (because stable fluorescence levels during licking occurred after three licks; see Fig. $7 A$ ), the remainder of the lick events, and the time period after licking stopped. During the initial three licks, fluorescence was estimated from the linear fit in Figure $7 B$ and the ratio of mean fluorescence to mean lick rate at the third lick. Fluorescence estimates during the remaining lick events were based on the linear fit for $4 \mu \mathrm{l}$ trials in Figure $3 F(\sim 2.8$ a.u./Hz). Finally, the drop in fluorescence after licking stopped was modeled to follow the average decay rate measured from data in Figure 7A $(\tau=0.91 \mathrm{~s})$, qualitatively accounting for the off-kinetics of the $\mathrm{Ca}^{2+}$ sensor. The 10 largest peaks for each session were chosen as " $n$ trials" for comparison to previous and subsequent trials in Figure $7 E$.

Plots were created and linear fits calculated using Prism 6 (GraphPad Software). All error bars indicate SEM. Significance was calculated using a two-sample Student's $t$ test unless noted otherwise. Figures were generated in Illustrator CS6 (Adobe Systems). 
A
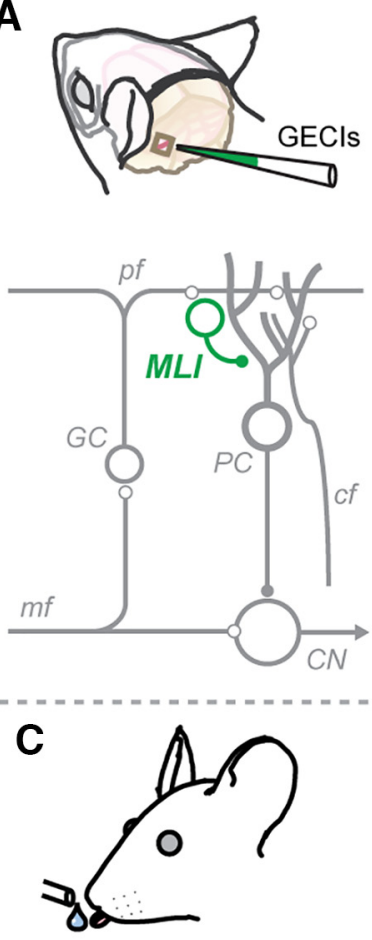

D
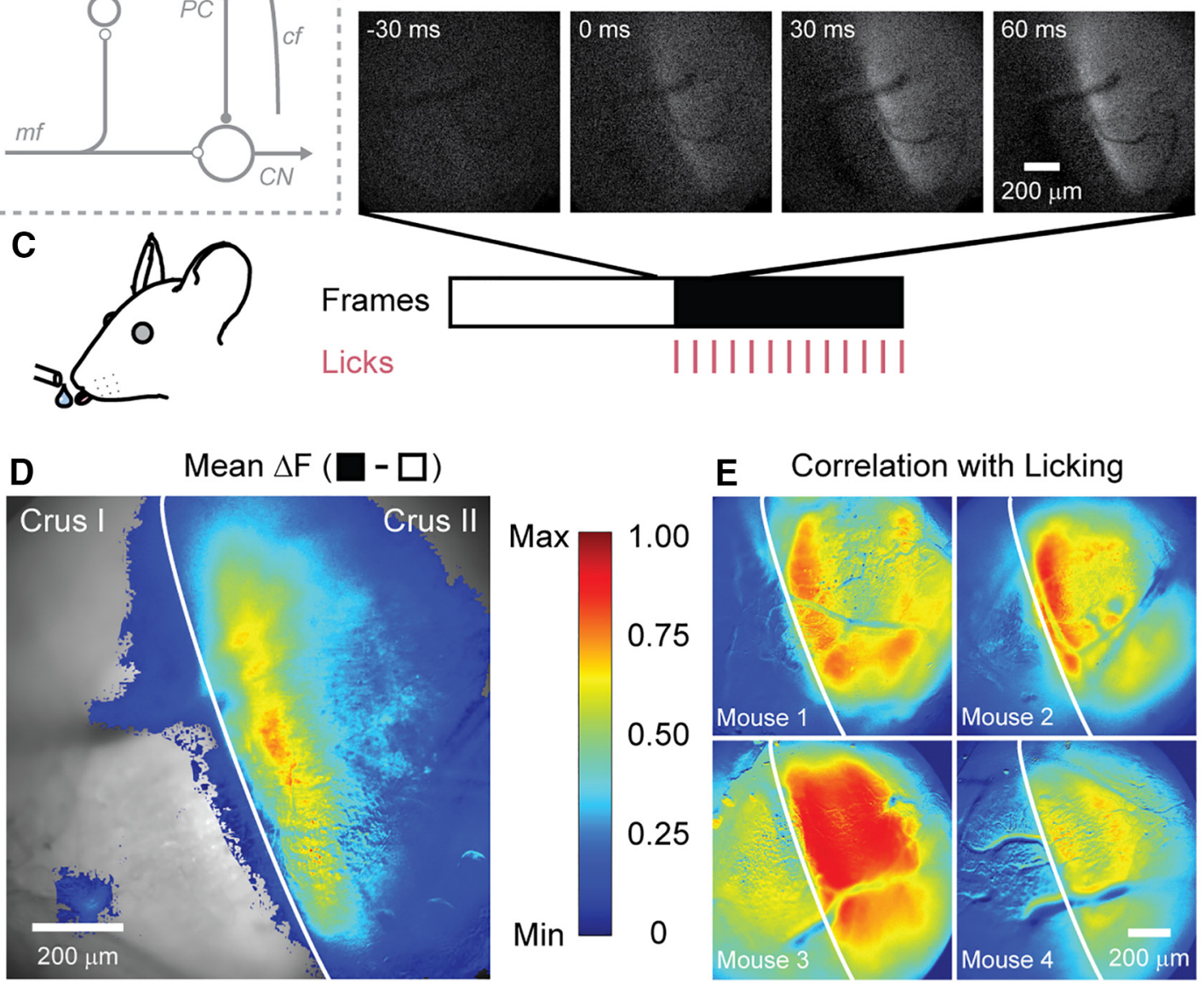

Frames

Licks
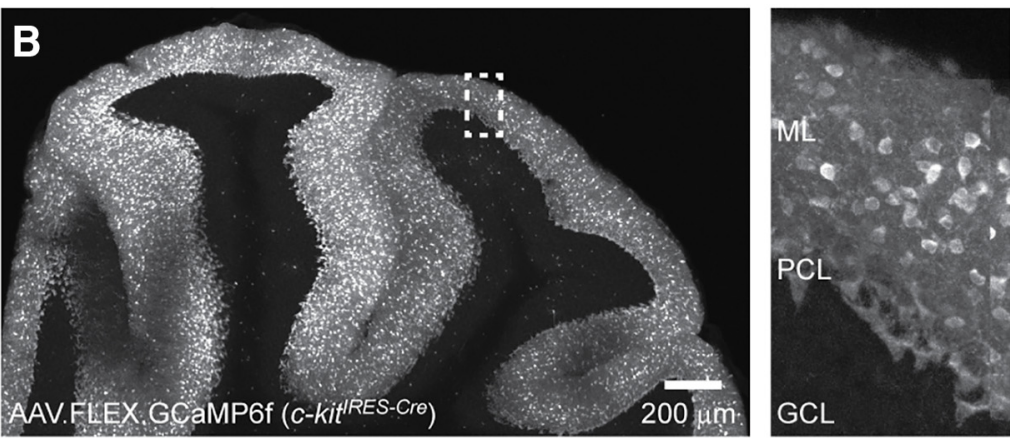

$200 \mu \mathrm{m}$

\section{E Correlation with Licking}

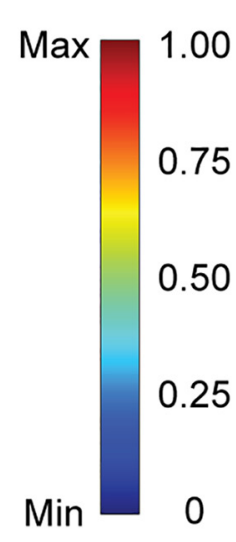

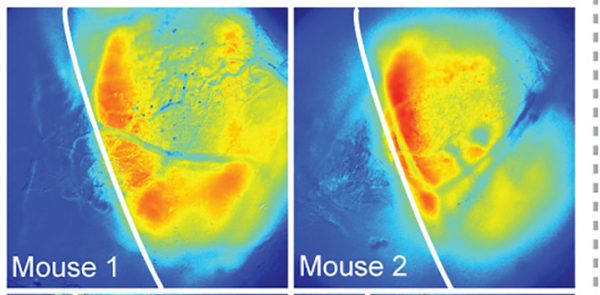

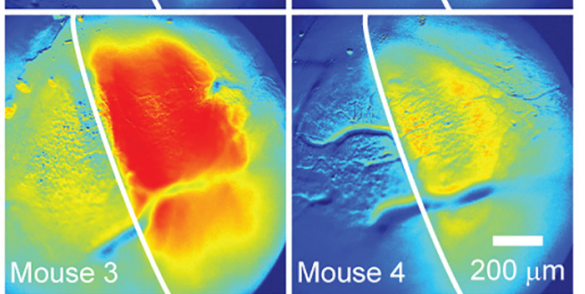

$\mathbf{F}$

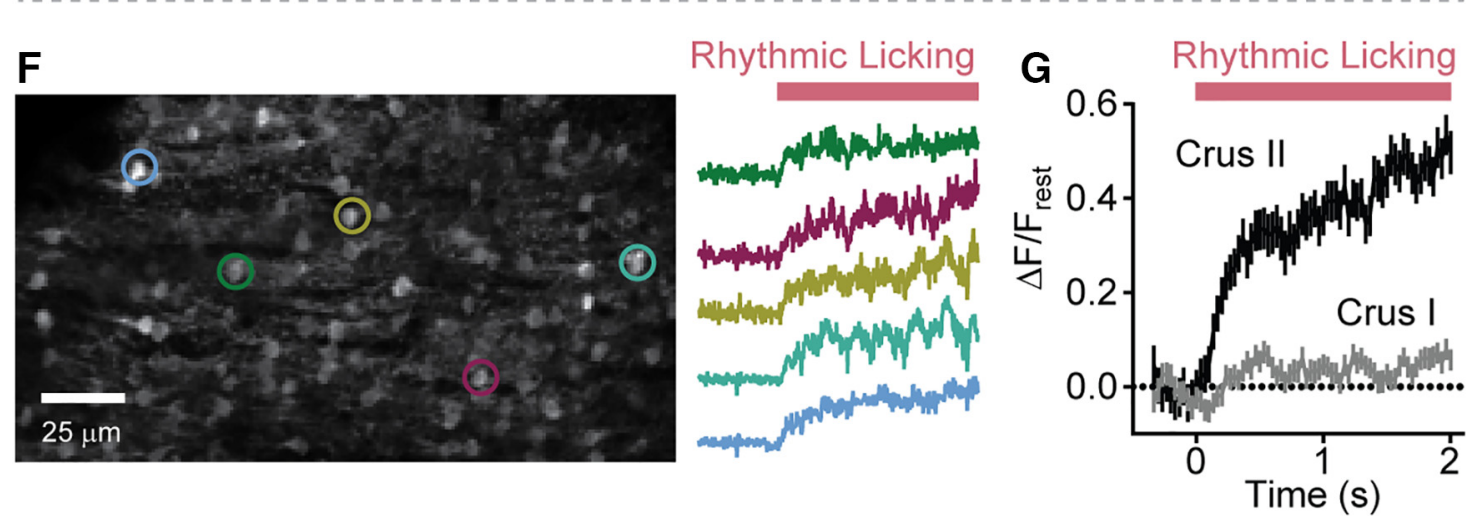

Rhythmic Licking

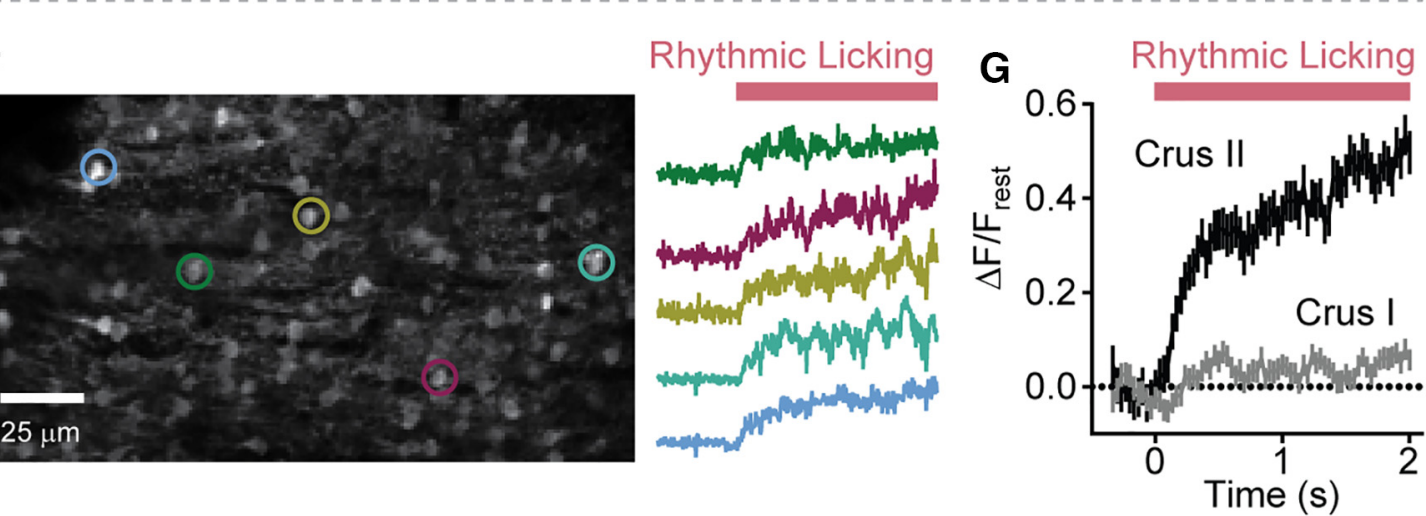

Figure 1. Movement-related $\mathrm{Ca}^{2+}$ activity in MLIs in the lateral cerebellum. $\boldsymbol{A}$, Illustration of the cranial window location and injection site for AAVs containing Cre-dependent genetically encoded $\mathrm{Ca}^{2+}$ indicators. At the bottom, a simplified circuit diagram of the cerebellum is shown, with MLIs highlighted in green. pf, parallel fiber; $\mathrm{GC}$, granule cell; $\mathrm{PC}$, Purkinje cell; $\mathrm{mf}$, mossy fiber; Cf, climbing fiber; CN, cerebellar nuclei. B, Sagittal view of viral-mediated GCaMP6f expression in the cerebellar cortex of a c-kit ${ }^{R E S-c r e}$ mouse. A higher-magnification view of the boxed region is shown on the right. ML, Molecular layer; $\mathrm{PCL}$, Purkinje cell layer; $\mathrm{GCL}$, granule cell layer. $C$, Select images from a time series collected using wide-field fluorescence microscopy $(30 \mathrm{~Hz})$ before and after (white and black regions, respectively) the mouse began licking ( $0 \mathrm{~ms}$; licks are indicated by tick marks). $\boldsymbol{D}$, Difference image (black minus white frames from $\boldsymbol{C})$ showing (Figure legend continues.) 


\section{Results}

\section{Widespread movement-related activity in MLIs}

We used in vivo $\mathrm{Ca}^{2+}$ imaging to measure the activity of cerebellar MLIs during the performance of a movement task in awake mice. Genetically encoded $\mathrm{Ca}^{2+}$ indicators (GECIs; GCaMP6f or RCaMP2; see Materials and Methods) were transduced in MLIs using viral delivery of a Cre-dependent construct in $c$ - $k i t^{\text {IRES-Cre }}$ mice, a driver line with selectivity for this cell type (Figs. $1 A, B$ ). Robust GECI expression was notable in MLIs across multiple lobules. Fluorescent cells were apparent throughout the molecular layer including both stellate and basket cells (pinceaux are visible in Fig. 1B). However, we did not attempt to distinguish these two cell types in our experiments. Using wide-field epifluorescence imaging, we recorded activity as a population response without regard to individual neurons. Optical recordings were targeted to the area of the lateral cerebellum that included Crus I and II, lobules that encode sensorimotor representations of the perioral facial extent and have been implicated in the rhythmic control of licking (Welsh et al., 1995; Bryant et al., 2010; Gaffield et al., 2016). In head-restrained mice trained to consume water from a port, we observed clear increases in the population activity of MLIs at the onset of ad libitum licking (Fig. 1C). Population activity was widespread and lobule specific. Movement-evoked fluorescence changes were apparent in a broad band along the transverse axis of Crus II bordering the fissure with Crus I but were notably absent in this neighboring lobule despite sporadic $\mathrm{Ca}^{2+}$ activity in this region that was uncorrelated with licking. Peak fluorescence changes in Crus I during these periods were not significantly different from those observed in Crus II during licking ( $p=0.09, n=12$ trials from 4 mice), suggesting an equivalent amount of GECI expression in MLIs from each lobule. The pattern of MLI activity in Crus II was similar across animals (Fig. 1D,E) and appeared devoid of distinct substructure (e.g., parasagittal zones), indicative of common response properties across coactive interneurons.

To examine MLI activity at cellular resolution, we turned to two-photon resonant scanning microscopy acquiring time-series images at high frame rates in these same mice (Fig. $1 F$ ). As expected from the population response, individual MLIs in Crus II were robustly activated at the onset of licking. The average activity profile of MLIs was sustained during ongoing movement, a lick-related response clearly absent in MLIs in Crus I (Fig. 1G). To more carefully determine the relationship between MLI Ca ${ }^{2+}$ activity and behavior, we provided water aliquots at regular intervals $(0.5 \mathrm{~Hz})$. Despite episodic allocation, mice tended to lick continuously due to a strong desire for fluid intake while under water restriction (Fig. 2A). Analysis of individual MLIs showed that, in addition to sustained $\mathrm{Ca}^{2+}$ transients during prolonged bouts of licking, there were sharp increases in $\mathrm{Ca}^{2+}$ activity dur-

\section{$\leftarrow$}

(Figure legend continued.) the mean fluorescence change in the MLI population $\mathrm{Ca}^{2+}$ response induced by licking. Superimposed over the imaging location are $\Delta F$ values $>0$, color coded on a linear scale from minimum to maximum (normalized data) according to the scale bar on the right. The vertical white line demarcates the boundary between Crus I and Crus II. Data represent an average of four mice. $\boldsymbol{E}$, Examples from four mice showing the correlation of each pixel value with licking (see Materials and Methods). Images are color-coded based on the scale bar to the left. $\boldsymbol{F}$, High-resolution fluorescence image of GCaMP6f-expressing MLIs acquired using two-photon laser scanning microscopy. Fluorescence traces from individual cells, corresponding to color-coded ROls, during the onset of rhythmic licking are shown on the right. $G$, Average $\mathrm{Ca}^{2+}$ response for MLIs in either Crus II (black line; $n=240$ cells from 3 mice) or Crus I (gray line; $n=240$ cells from 4 mice) during rhythmic licking. In half of the trials ( 120 cells from 2 mice), both lobules were imaged simultaneously. ing each episode of water allocation (Fig. 2B). Close inspection revealed distinct accelerations in the instantaneous lick rate each time water was provided (Fig. 2C; for instantaneous lick rate calculation, see Materials and Methods), perhaps reflecting a behavioral strategy to rapidly consume a droplet when available, a result more apparent when averaged over several trials (Fig. 2D). We quantified the association between cell activity and movement by plotting the correlation between the derivatives of both the MLI $\mathrm{Ca}^{2+}$ response and instantaneous lick rate (Fig. $2 E$ ). A prominent, zero-centered peak in the correlation indicated a strong relationship between cell activity and this kinematic feature, confirming that MLIs are constituent participants of cerebellar circuits encoding movement during the consumption of water.

\section{MLI activity closely tracks movement rate}

To better understand how the salient aspects of movement are encoded in this ensemble of MLIs in Crus II, we modified our behavioral task to include a tone indicating the episodic availability of water. Mice quickly learned this association by withholding licks before the tone sounded then licking until the dispensed droplet was consumed (Fig. $3 A, B$ ). By varying the amount of dispensed water in a pseudorandomized manner, including trials without any water, we were able to manipulate task-dependent motor behavior. In trained mice, larger water rewards resulted in faster and more persistent licking, whereas in the absence water, licking was slow and abbreviated (Fig. 3C).

Strikingly, the mean MLI $\mathrm{Ca}^{2+}$ response closely correlated with the patterned change in instantaneous lick rate used by mice for each trial condition (Fig. $3 D, E$ ). This correlation was nearly absent if the analysis was performed using shuffled data (Fig. $3 E$ ), indicating a high degree of specificity between neural activity and the rate of movement used for each task condition. This was evaluated in greater depth by plotting the relationship between the peak amplitudes of MLI $\mathrm{Ca}^{2+}$ responses and corresponding lick rates for individual trials across sessions (Fig. $3 F$ ). Although there was considerable overlap in the distributions for each condition, trial-over-trial averages showed a clear linear relationship between the amplitude of the $\mathrm{Ca}^{2+}$ response and peak lick rate (Fig. 3G). Additionally, in select trials sharing a similar lick rate regardless of task condition, the probability distribution of $\mathrm{Ca}^{2+}$ amplitudes was essentially the same (Fig. $3 H$ ). This result strongly indicates that overt sensory information reporting task-specific variables (e.g., water volume) was not represented in the $\mathrm{Ca}^{2+}$ activity of MLIs. Similarly, swallowing, absent on trials without water, did not contribute to MLI $\mathrm{Ca}^{2+}$ activity.

Analysis of lick-associated movement, captured using highspeed videography simultaneously with MLI activity measurements (Fig. 4A), showed that head-restrained mice adjusted their gross motor pattern during licking. Faster lick rates (i.e., shorter interlick intervals) were accompanied by briefer epochs with the mouth open or closed that changed in a coordinated manner (Fig. 4B,C). Tracking the speed of tongue movement (Fig. 4D) showed that lick rate is correlated with tongue velocity during both extension and retraction phases (Fig. $4 E$ ), suggesting that this kinematic variable is a participant feature determining the overall lick rate. In some trials, mice withheld licking but articulated their lower jaw with a resulting movement amplitude $\sim 40$ $50 \%$ of that during a single, full lick (Fig. $4 F$ ). During such actions there was a minimal amount of evoked MLI $\mathrm{Ca}^{2+}$ activity, indicating that jaw movement is not encoded in the responses of MLIs in this region of Crus II (Fig. 4F). 
A

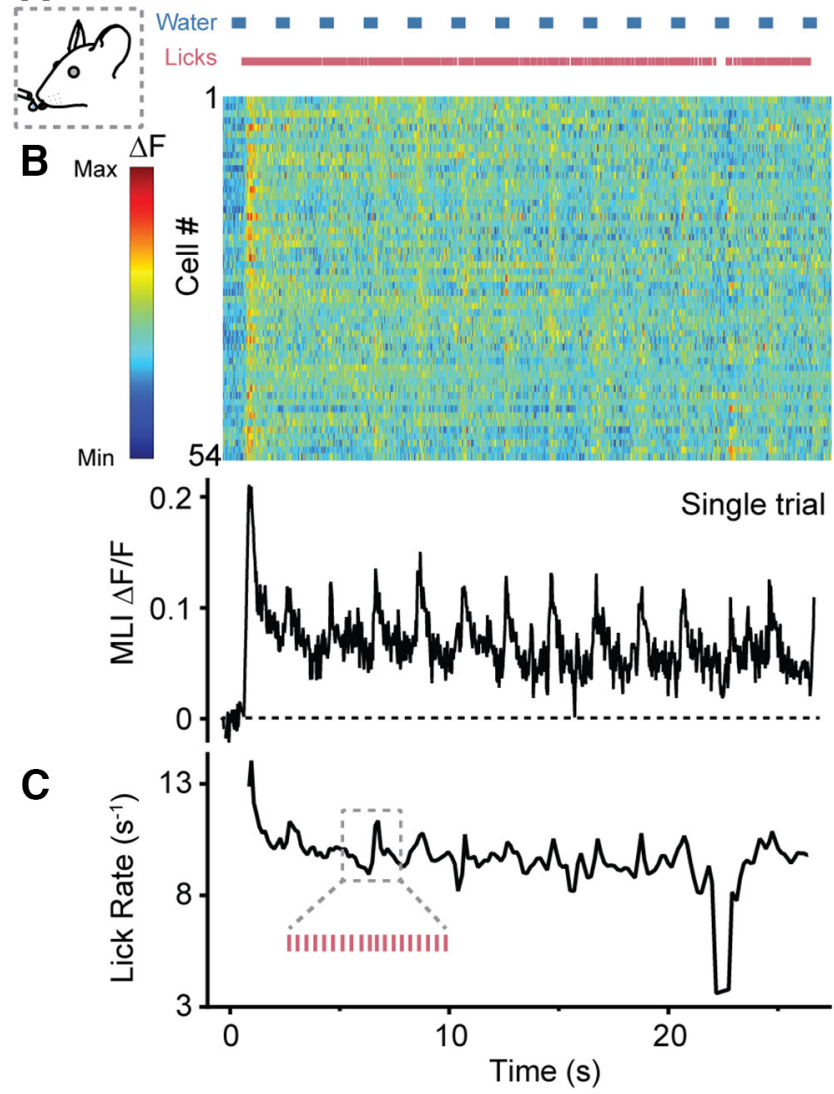

D
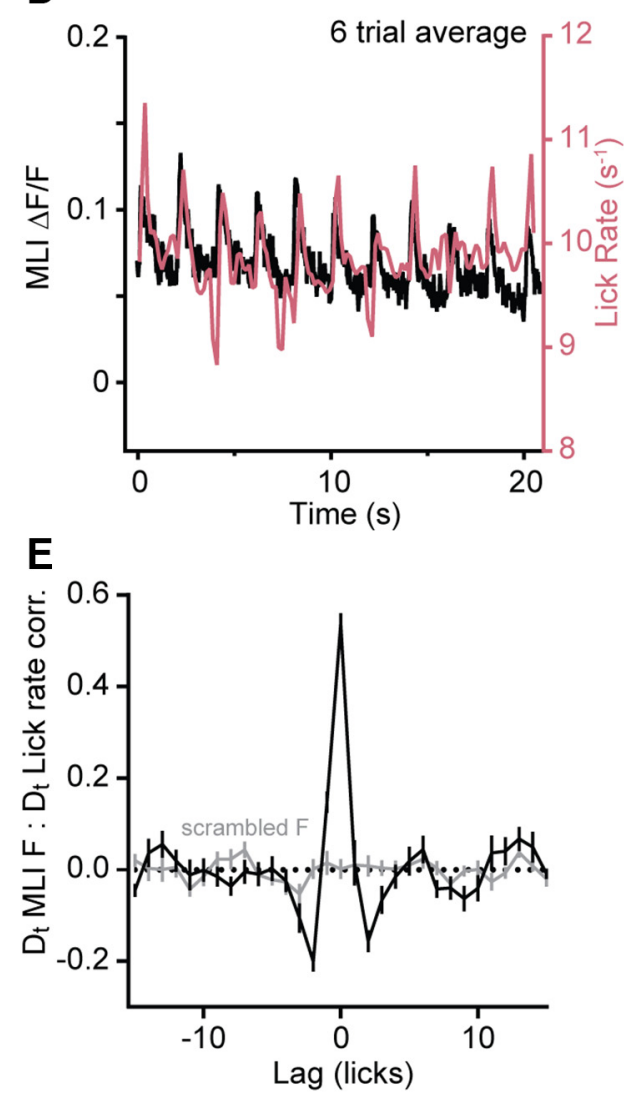

Figure 2. Transient increases in MLI $\mathrm{Ca}^{2+}$ activity during sustained licking. $\boldsymbol{A}$, During a single trial of the task, water was dispensed in regular intervals (blue bars) and the mouse licked continuously ad libitum. (Pink ticks mark individual licks as measured by contact with the lick port.) $B$, Activity measurements for individual MLIs in a field of view during the bout of sustained licking shown above. Changes in MLI fluorescence are normalized according to the color bar on the left. The average single-trial Ca ${ }^{2+}$ response for all cells is shown below. $\boldsymbol{C}$, Plot of instantaneous lick rate derived from the same lick bout above. Inset, A magnified subsection showing detected licks. D, Average measurements of MLI Ca ${ }^{2+}$ activity (black) and lick rate (pink) from six trials of licking bouts

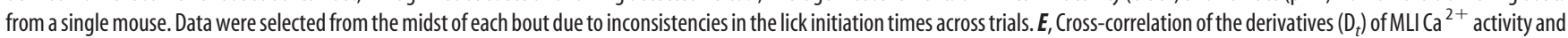
lick rate (black line). For scrambled fluorescence data, there was no apparent peak in the correlation (gray line). Data include 12 trials from three mice.

It is believed that the cerebellum receives copies of motor commands for planned movements whose encoding temporally preempts or coincides with the execution of the intended action (Wolpert and Miall, 1996). In contrast, sensory feedback related to movement is expected to arrive later than the motor commands themselves due to peripheral propagation delays. We observed a lead in the onset of MLI Ca ${ }^{2+}$ activity relative to the initiation of any visible mouth movement observed using highspeed videography of single, isolated lick events (Fig. 4G). To estimate the duration of unobserved tongue motion while the mouth was closed, we extrapolated the tongue's velocity as it becomes visible $(82 \mathrm{~mm} / \mathrm{s})$ with the estimated distance traveled by the tongue from rest to outside the mouth $(<1.5 \mathrm{~mm})$. Taking this $18 \mathrm{~ms}$ delay into account, we estimate that MLI activity leads lick initiation by $\sim 30 \mathrm{~ms}$. This period is similar to that observed for phase-lead Purkinje cells that fire during the initiation of a licking bout (Bryant et al., 2010). These results indicate that these MLIs encode rate information related specifically to the lick cycle including mouth open duration, mouth closed duration, and tongue velocity but not jaw movement or swallowing.

Movement trajectory is not encoded in the activity of MLIs Movement is a variable rich behavior encompassing not only changes in time but also space. To determine whether MLIs encode positional information regarding movements associated with licking, we took advantage of the natural trial-to-trial vari- ance in motor trajectory that mice use during different bouts of water consumption. We partitioned select cued licking trials based on their trajectory bias toward either the upper or lower region of the lick port, as evident in both tongue and jaw position (Fig. 5A). In this analysis, the average position of the tongue and lower jaw were shifted ventrally by $\sim 240$ and $370 \mu \mathrm{m}$, respectively, during lick bouts frequenting the lower portion of the port (Fig. 5A). During these modestly different trajectories, movement-related $\mathrm{Ca}^{2+}$ responses in MLIs continued to be dominated by activity related to lick rate (Fig. $5 B$ ).

In the adaptive filter model of cerebellar function, predictable features of sensory input are canceled during self-motion but, following mismatches between intended motor action and actual outcome (e.g., missing a step while climbing stairs), uncanceled feedback is reported through instructive signals that guide rapid updating (Bastian, 2006; Sawtell, 2017). To examine whether the unintended alteration of predictable sensorimotor associations is encoded in the $\mathrm{Ca}^{2+}$ activity of MLIs, we rapidly moved the lick port out of reach immediately before a cued bout of licking obfuscating sensory stimulus provided by lick port contact (Fig. $5 C)$. Despite the absence of any feedback, the mouse would continue to generate several licks. However, in these interspersed probe trials, the mean MLI Ca ${ }^{2+}$ response was exactly comparable to that recorded in normal cued trials where water was not provided, a condition that generated a similar rate of initial licking (Fig. 5C). In a related manipulation, we moved the lick port 

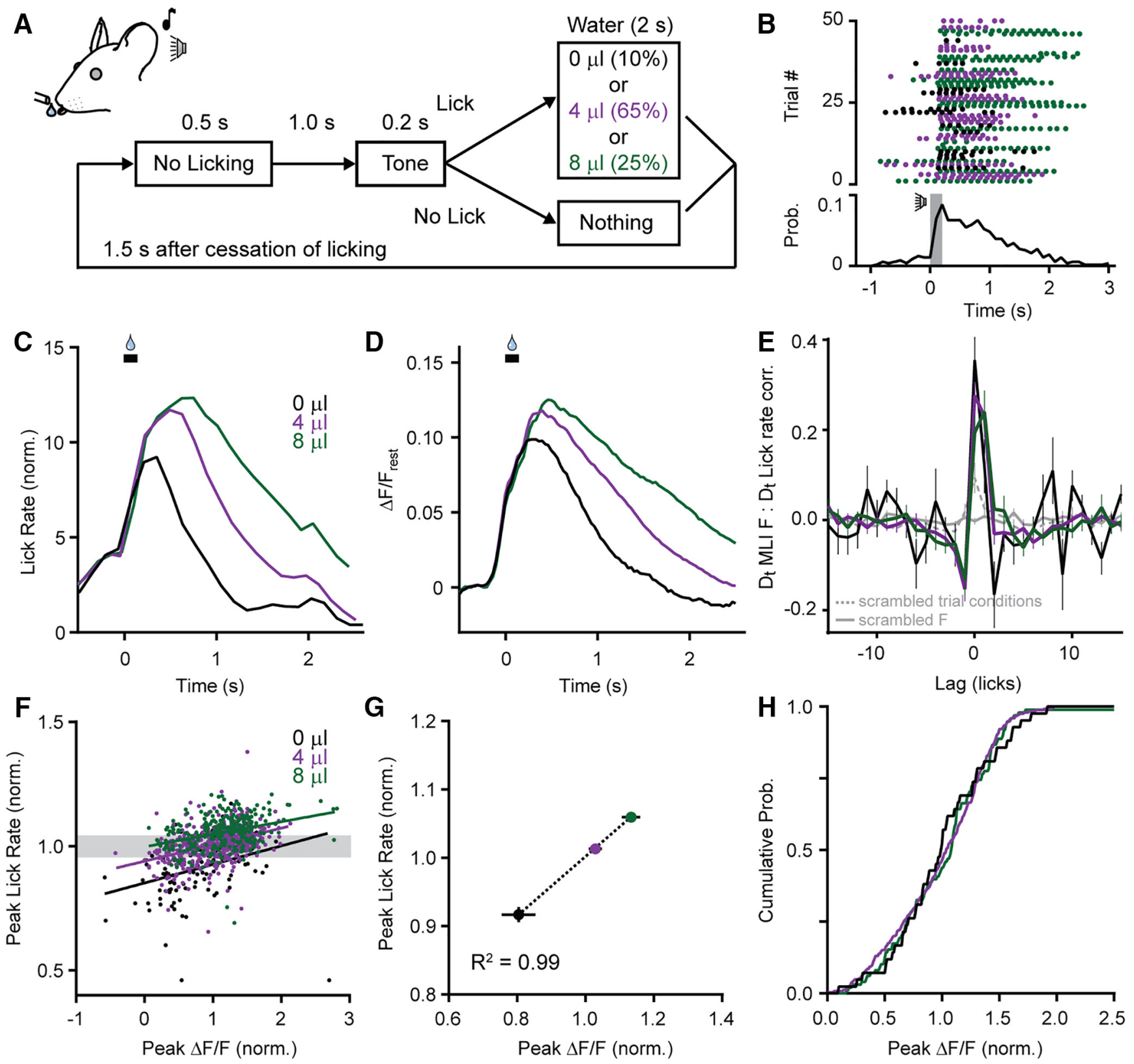

Figure 3. MLIs encode movement rate in their $\mathrm{Ca}^{2+}$ activity. $A$, Diagram of the cued licking task showing trial structure. A tone indicates the availability of water delivered pseudorandomly in three different aliquots. (Volumes are color coded.) B, Timing of licks for consecutive cued trials. Bottom, A plot of the average lick probability for all licking bouts during the session. The tone cue is indicated in gray. $\boldsymbol{C}$, Average lick rate during cued trials sorted based on the volume of dispensed water. To correct for differences in lick bout duration, data were normalized across conditions to the lick probability at each time point and then aligned to the opening of the water valve (black bar). $\boldsymbol{D}$, The average lick-induced $\mathrm{Ca}^{2+}$ response in MLIs varied depending on trial condition.

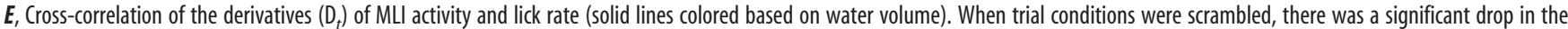
cross-correlation (dashed gray line). Also shown is a trace where fluorescence was scrambled (solid gray line). $\boldsymbol{F}$, Data across all the trials were normalized to the respective mean (either peak $\Delta F / F$ or peak lick rate) for each session ( 7 sessions from 5 mice; average of 126 trials per session) to properly relate these distributions across different sessions, and plotted to compare the peaks of the MLI $\mathrm{Ca}^{2+}$ response and lick rate. There was a positive correlation for each trial condition, although in many trials, lick rates overlapped despite differences in the volume of dispensed water. $\mathbf{G}$, The relationship between peak $\mathrm{MLI} \mathrm{Ca}^{2+}$ activity and peak lick rate, plotted as averages for each condition across mice, was well fit with a linear regression. $\boldsymbol{H}$, Cumulative probability from the subset of fluorescence data where lick rates were similar despite differences in the volume of dispensed water (data points are contained in the gray box in $F$, one SD in width surrounding the mean peak lick rate).

out of reach in the midst of a cued bout of licking. In the first lick attempt immediately following this perturbation, the tongue moved erratically as it failed to make contact with the port (Fig. $5 D$ ). Subsequent licks during the bout were long and sweeping as the mouse searched for the lick port with the tongue extending $\sim 40 \%$ further out of the mouth compared to normal licks with the port in place. Although there were obvious transitions from normal to erratic licking including dramatic changes in trajectory, we observed no major deviations in MLI responses across mice. Instead, movement-evoked $\mathrm{Ca}^{2+}$ activity closely tracked instantaneous lick rate (Fig. 5D), which slowed as the search phase commenced. Together, we find little evidence for encoding signals associated with either tongue trajectories (at least in the plane parallel to the body axis that we observed with high-speed videography) or the disturbance of predictable sensorimotor associations in the mean $\mathrm{Ca}^{2+}$ activity of MLIs during rhythmic movement. 
A
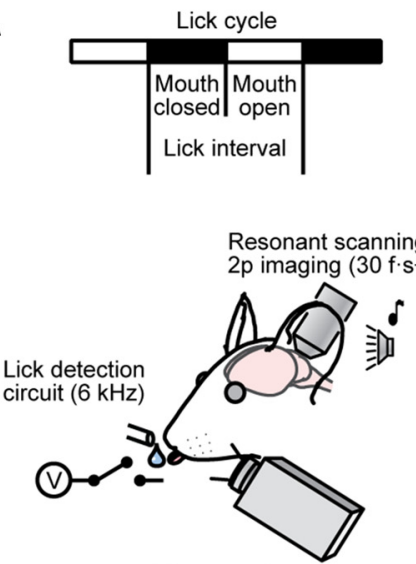

High speed

videography $\left(1000 \mathrm{f} \cdot \mathrm{s}^{-1}\right)$
B

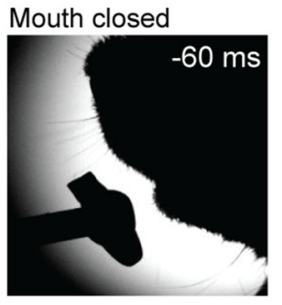

C

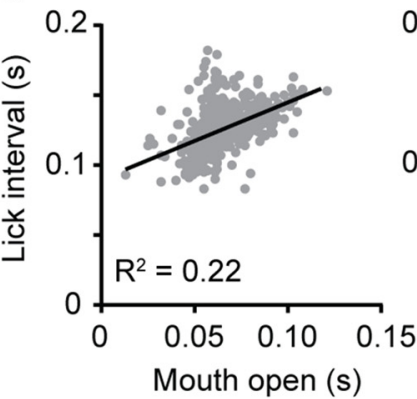

Mouth opens

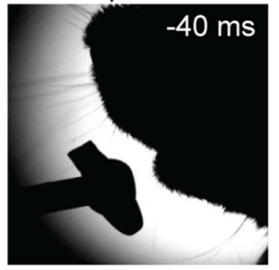

0.2

0.1

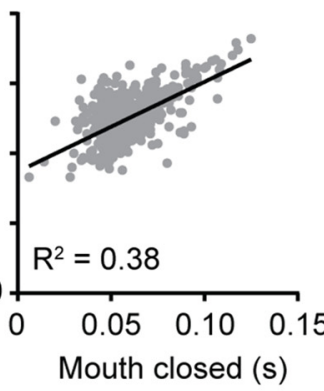

Lick port contact

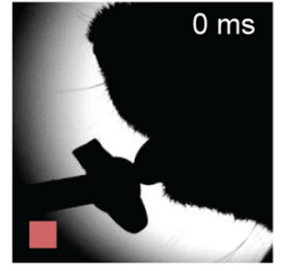

Mouth closes

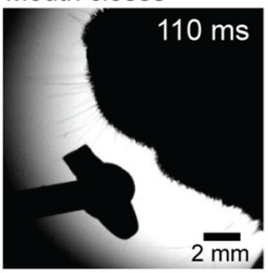

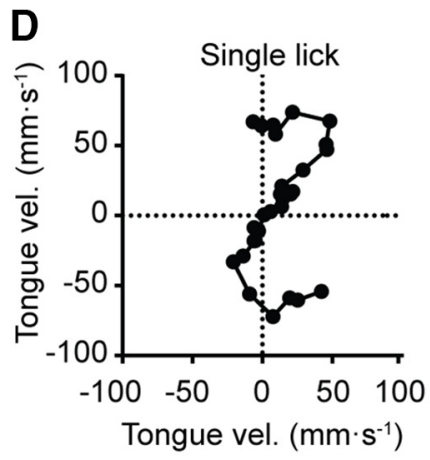

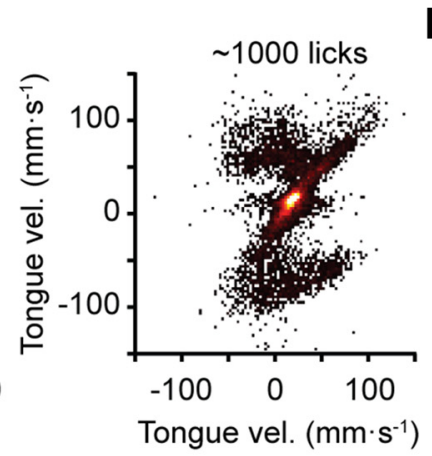

$E$
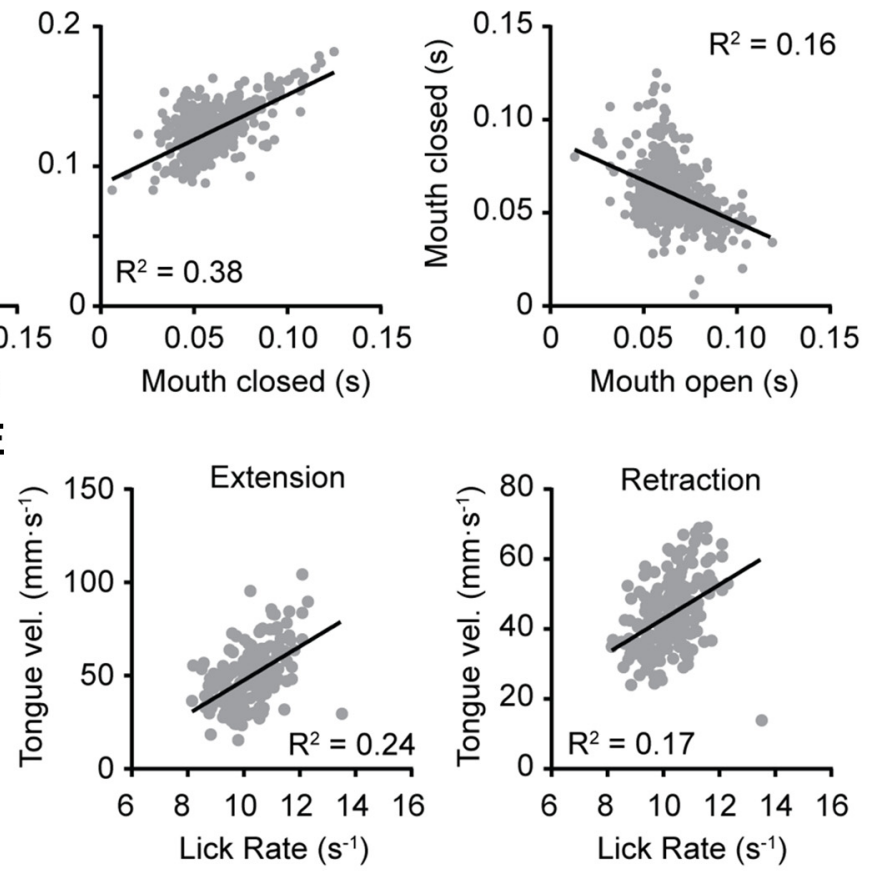

F
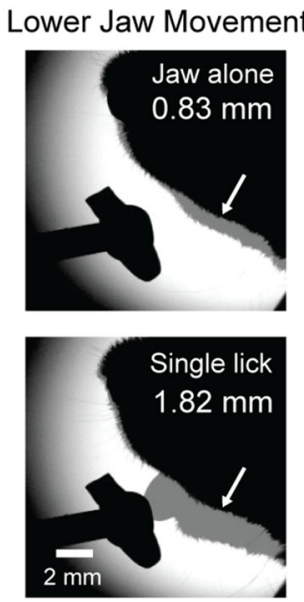
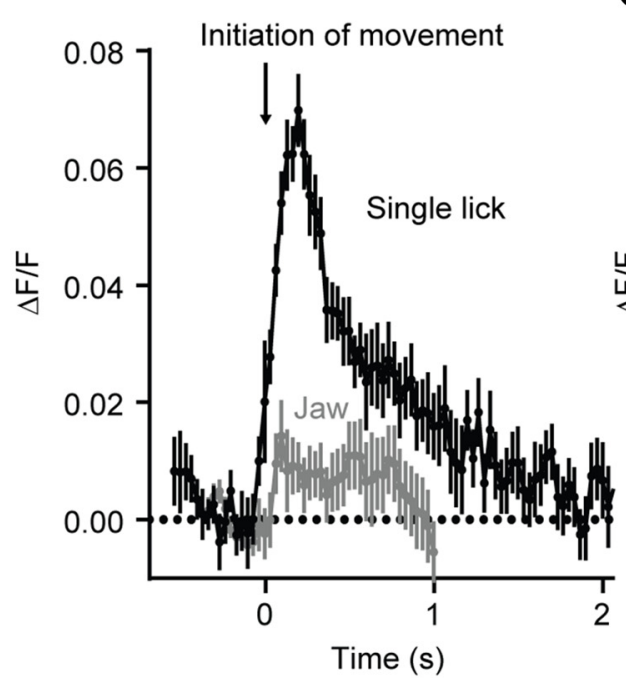

G

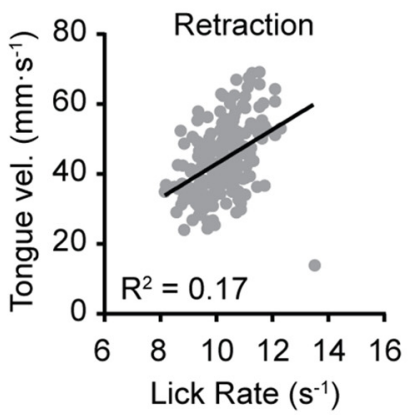

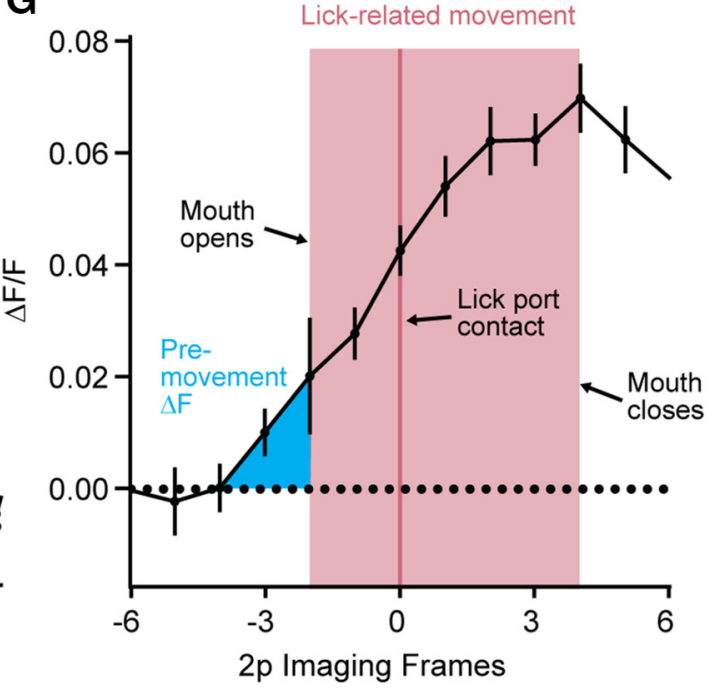

Figure 4. Coordinated patterns of motor output during water consumption. $A$, Diagram depicting of the recording configuration including simultaneous acquisition of high-speed videography and two-photon $\mathrm{Ca}^{2+}$ imaging. $\boldsymbol{B}$, Select video images showing the timing of distinct phases of movement during an individual lick in a bout of cued licking. Detection of the lick, registered using a lick-detection circuit (in pink; $0 \mathrm{~ms}$ ), is apparent in the image as the tongue makes contact with the lick port. C, Plots showing the temporal coordination of distinct phases of licking. Shorter interlick intervals are associated with briefer epochs with the mouth open or closed, movement phases that covary in coordination with one another (data obtained from 608 licks, shown in gray, from 3 mice). D, Tracking tongue velocity during a single lick using images captured during high-speed videography. On the right, a heat map of velocity tracks from many licks across bouts from a representative mouse is shown. $\boldsymbol{E}$, The relationship between average tongue velocity and lick rate during tongue extension (left) or tongue retraction (right). $\boldsymbol{F}$, Left, Representative images showing maximum extent of lower jaw movements during a trial without a lick (top) or with a single lick (bottom). Arrows point to the grayed regions where the amplitude of the jaw movement was measured. Right, Plot comparing mean $\mathrm{MLI} \mathrm{Ca}^{2+}$ activity during a single lick (black line) or during lower jaw movement alone (gray line). Both traces are aligned to the initiation of any visible movement. $G$, Plot showing the timing of $\mathrm{MLI} \mathrm{Ca}^{2+}$ activity relative to the initiation of lick-related movement during an isolated lick. Timing is plotted based on the imaging frame obtained with resonant-scanning two-photon microscopy. Mouth opening and closing were determined from high-speed videography. Lick contact is registered from the detection circuit. 
A
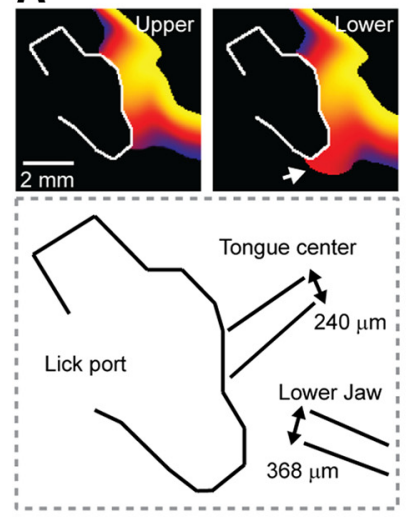

B

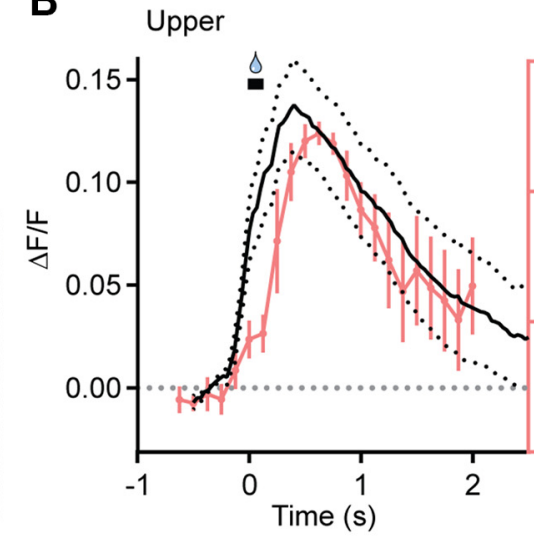

Lower

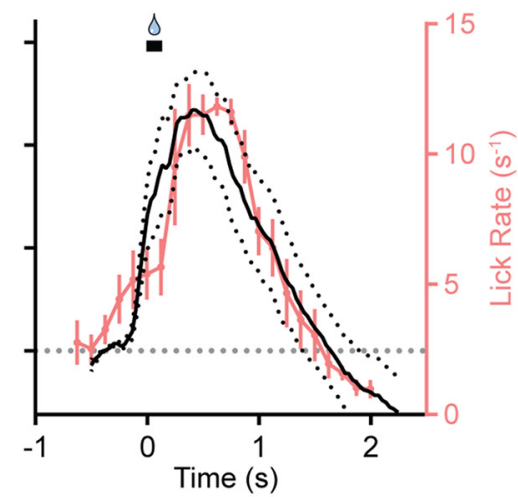

C

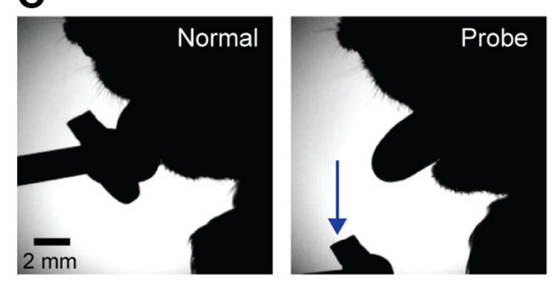

D

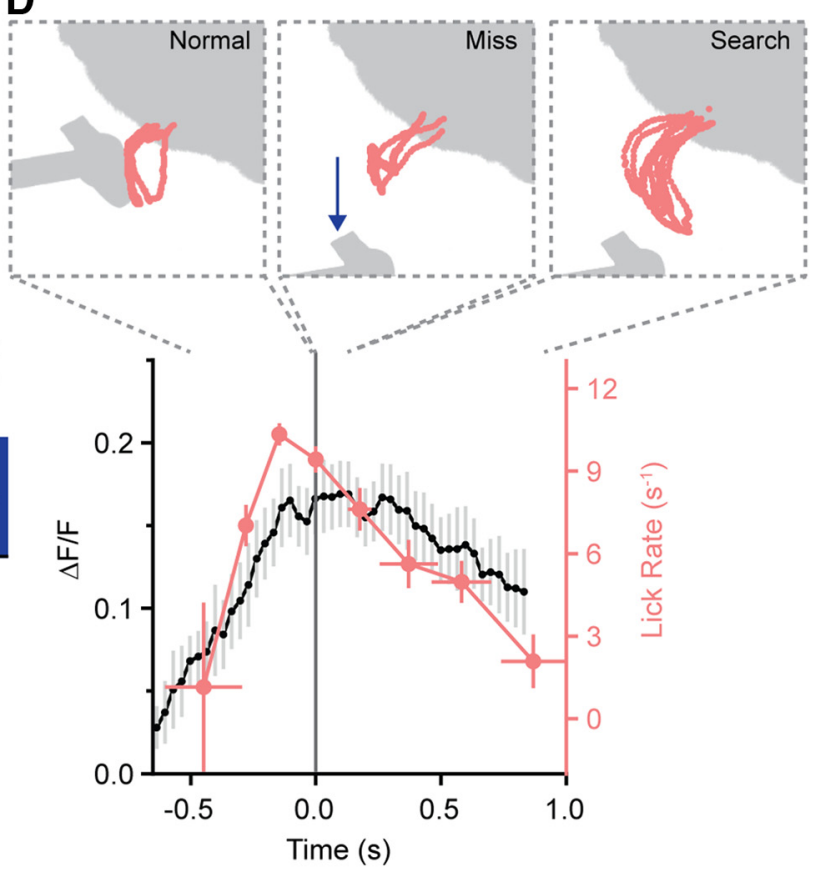

Figure 5. Movement trajectory is not represented in MLI activity. $\boldsymbol{A}$, Heat map of cumulative tongue and jaw position during bouts of licking selected dependent on a trajectory bias to either the upper or lower portion of the lick port. For the lower lick bouts, an arrow marks the tongue extending below the port. The diagram below shows the mean positions of the center of the tongue and lower jaw for partitioned trials ( $n=209$ and 160 trials for licking biased to the upper or lower portion of the port, respectively; 5 mice). $\boldsymbol{B}$, Average movement-related Ca ${ }^{2+}$ response in MLIs during two distinct lick trajectories for the same cohort of mice. $C$, High-speed video images from a trial of normal licking ( $0 \mu$ l of dispensed water) or a probe trial where the lick port was moved out of reach immediately before the tone cue. Below, average $\mathrm{Ca}^{2+}$ responses in MLIs for both normal and probe trials ( $n=68$ and 27 trials, respectively; 5 mice). Inset, The corresponding mean initial lick rates (normal and probe trials, black and blue, respectively). Lick rates are not significantly different ( $t$ test, $p=0.775)$. $\boldsymbol{D}$, Lick trajectories during different phases of a cued trial where the lick port was moved in the midst of a bout of licking. The scale bar from C applies. In the plot below, average MLI $\mathrm{Ca}^{2+}$ activity and instantaneous lick rate aligned to the time point $(t=0)$ where the lick port was moved ( $n=21$ trials; 7 mice).

\section{Correlated $\mathrm{Ca}^{2+}$ activity across the MLI ensemble}

Given that we observed robust encoding of movement kinematics in the mean $\mathrm{Ca}^{2+}$ activity of MLIs, we inquired whether there was diversity within their ensemble, with some MLIs tuned to particular aspects of motor behavior. However, arguing against this possibility, we found remarkable similarity in the responses of individual MLIs, as indicated by the high correlation of their average $\mathrm{Ca}^{2+}$ activity over trials of cued licking (Fig. 6A). Correlated $\mathrm{Ca}^{2+}$ activity did not degrade with distance between individual cells (Fig. 6B), a result repeatedly observed in imaging fields spread throughout the region of Crus II contained within our cranial window (Fig. 6C). Thus, these MLIs appear homogeneous in their response to rhythmic licking, indicating broad population tuning for encoding the rate of movement in their activity.

\section{Single-trial variance in MLI Ca ${ }^{2+}$ activity}

Accurate representation of information in a neural network benefits from broad tuning in a large population of neurons that must be flexible enough to rapidly adapt to dynamic changes if alteration of input stimuli is encountered. MLIs have been implicated as potential sites of plasticity for the consolidation of learning (Scelfo et al., 2008); therefore, any sensorimotor features predictive of adaptive stimuli may be transmitted through their activity. We first examined how reliably MLIs encode movement rate by monitoring for variance in their $\mathrm{Ca}^{2+}$ activity during 
individual trials of cued licking. To measure for this, we made an estimate of the expected ensemble $\mathrm{Ca}^{2+}$ response, based on average MLI activity, for an individual lick bout using the underlying lick pattern for that trial. Our transfer function (see Materials and Methods) accounted for the $\mathrm{Ca}^{2+}$ component relating to the total number of licks, determined from sorted trials based on the number of licks elicited during a bout (Fig. $7 A$ ), the relationship between the slope of the evoked $\mathrm{Ca}^{2+}$ response and initial lick rate (Fig. $7 B$ ), and the dynamics of the $\mathrm{Ca}^{2+}$ sensor used to measure activity. Examining repeated trials of cued licking ( $4 \mu \mathrm{l}$ aliquots only), we found a high correspondence for most trials between the predicted $\mathrm{Ca}^{2+}$ response in the MLI ensemble and the measured $\mathrm{Ca}^{2+}$ activity for that bout of licking (Fig. $7 C)$. However, there were clear instances where the movement-evoked $\mathrm{Ca}^{2+}$ response in MLIs was much greater than that predicted from changes in lick rate alone, representing about $7 \%$ of the total number of trials across mice (Fig. 7C,D). Although these deviations could be attributable to noise inherent in an adaptive neural network, we nevertheless searched for a behavioral correlate where additional coding information may be contained in the MLI $\mathrm{Ca}^{2+}$ response.

Recent work indicates that movementrelated neural activity in trials following instructional events may contain important information relevant for coding plasticity necessary for learning (Yang and Lisberger, 2014a,b; Khilkevich et al., 2016). Consequently, we sorted cued licking trials immediately before $(n-1)$ or just after $(n+1)$ large deviant peaks in MLI Ca ${ }^{2+}$ activity and examined for aberrant motor behavior in the preceding trial, specifically examining for changes in lick rate that would necessitate encoding for corrective kinematic action in this region. However, peak lick rate was the same across all trials (Fig. $7 E$ ), arguing against the possibility that a motor pertur-

bation in the preceding trial drove a significantly larger $\mathrm{Ca}^{2+}$ response in the MLI ensemble in the subsequent trial. To address this point more directly, we also examined probe trials where the lick port was unexpectedly moved out of reach during a bout of water consumption. However, the peak amplitude of the MLI $\mathrm{Ca}^{2+}$ response was unchanged in the trial following the perturbation compared to the trial immediately preceding it (Fig. $7 F$ ). Similarly, we failed to observe a measureable change in lick rate between these two trial conditions, indicating that behavior was unaffected in the trial immediately following the perturbation (Fig. 7G). Together, these results indicate that MLIs reliably encode movement rate within their ensemble; however, the accurate representation of this kinematic feature may be corrupted or
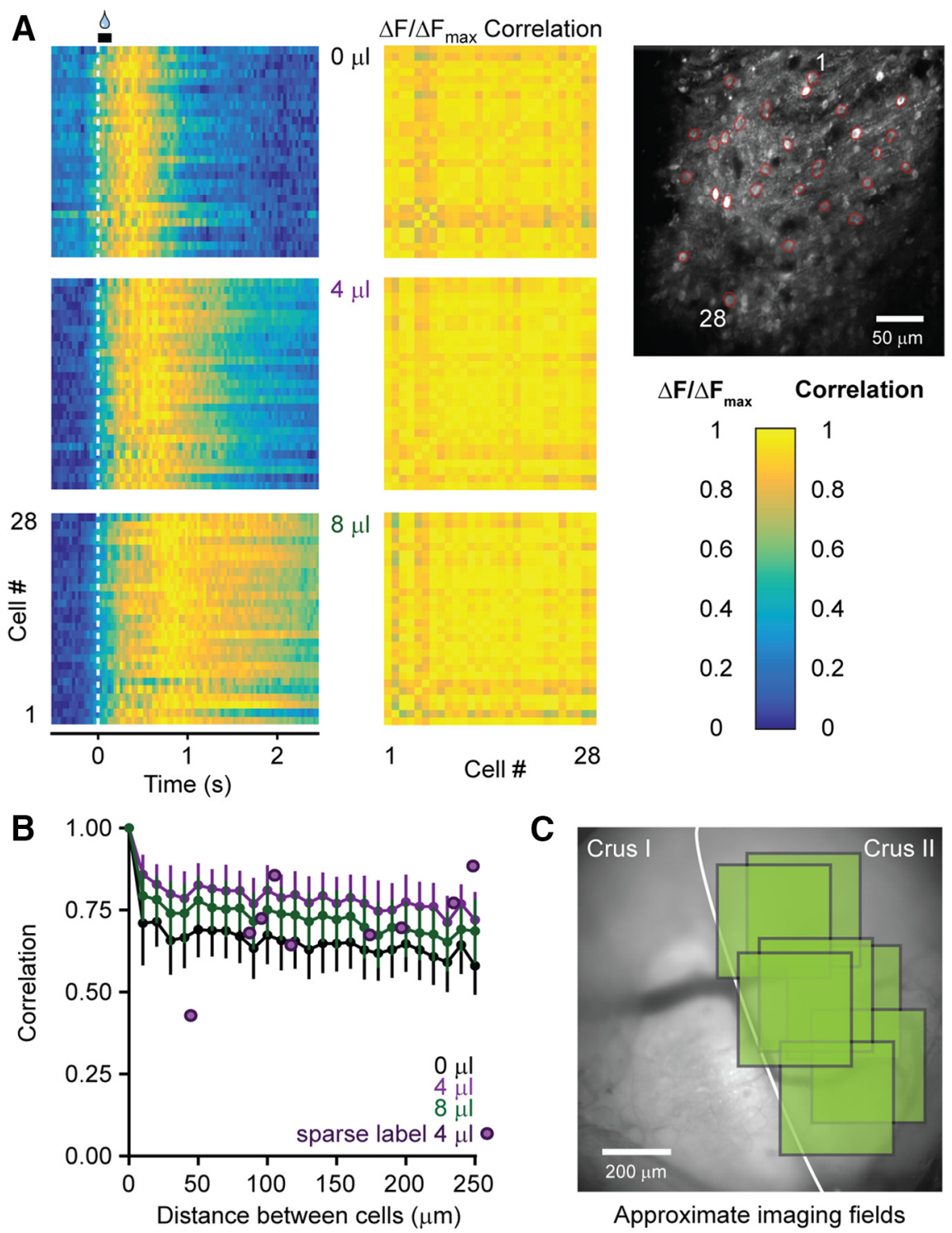

Approximate imaging fields

Figure 6. MLI activity is uniform across an ensemble. $\boldsymbol{A}$, Relative fluorescence changes induced in MLIs during a session of cued conditions. $\boldsymbol{B}$, Plot of average cell-to-cell correlation values versus the distance between each cell pair (colored lines, $n=225$ cells sentative cranial window overlaying Crus I and Crus II with approximate imaging field locations used to evaluate correlated activity (7 fields of view, marked in green, from 5 mice).

modulated in some trials, either by biological noise or an unknown sensorimotor variable that we have yet to identify.

\section{MLI activity influences movement rate}

MLI activity drives feedforward inhibition that shapes Purkinje cell spike output. The abrupt arrest of spontaneous Purkinje cell spiking by optogenetic-induced MLI activation can drive temporally precise movement in quiescent mice (Heiney et al., 2014). Conversely, the immediate increase of Purkinje cell spiking by optogenetic inhibition of MLIs can reduce motor action (Jelitai et al., 2016). These results indicate that molecular layer inhibition plays a prominent role in motor control. Therefore, to directly explore how the activity of MLIs in Crus II influence licking, we injected $c$ - $k i^{I R E S-C r e}$ mice bilaterally in lobules Crus II with AAV containing Cre-dependent hM4Di (Fig. 8A), an inhibitory engi- 

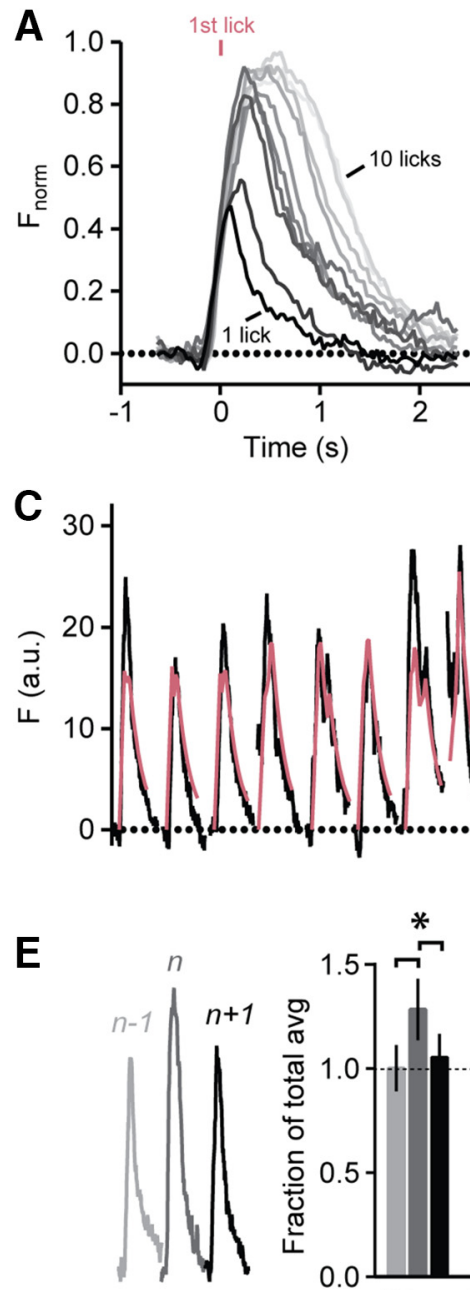
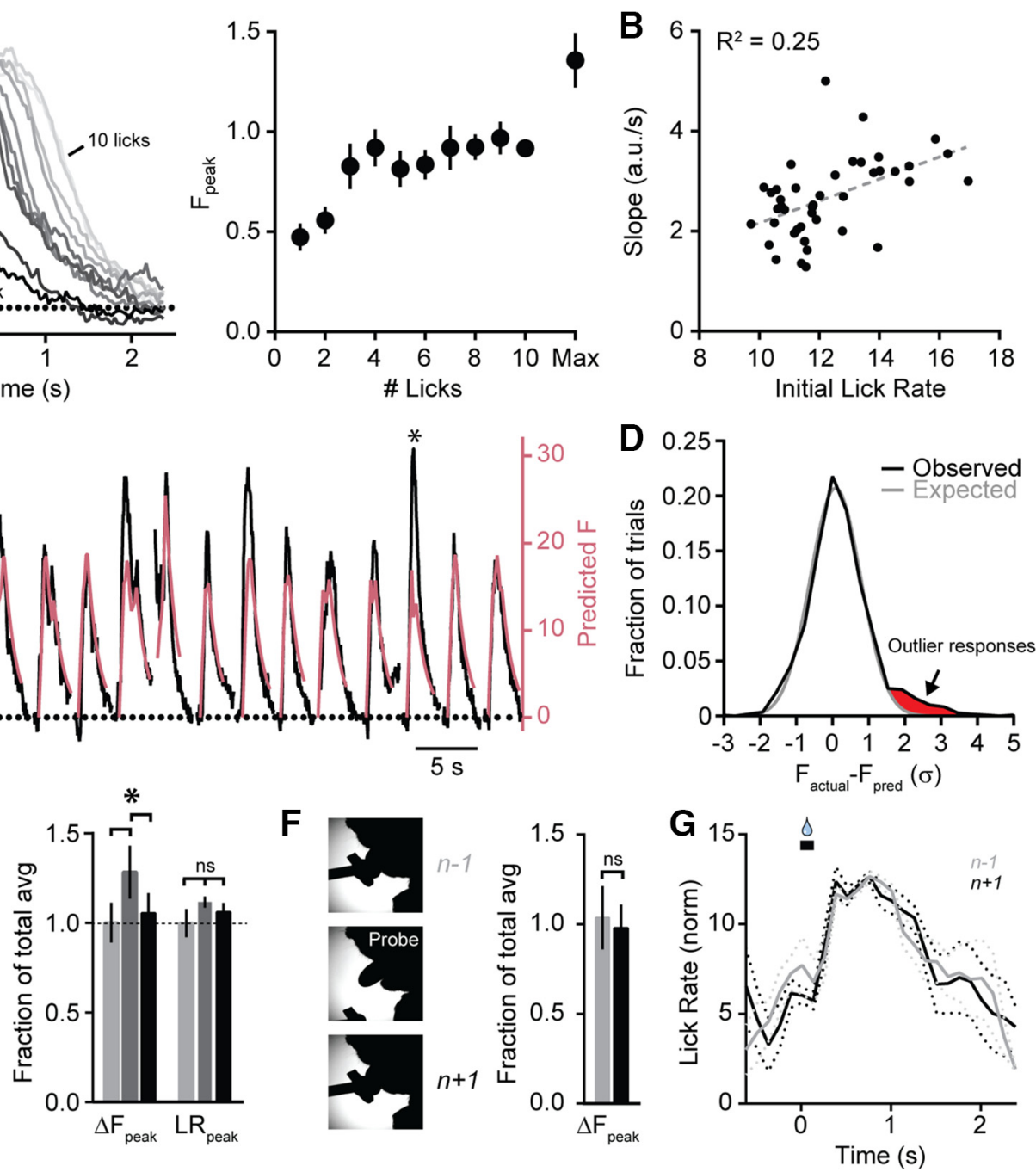

Figure 7. Movement rate cannot fully account for variability in MLI activity. $\boldsymbol{A}$, Lick-induced $\mathrm{Ca}^{2+}$ responses in MLIs sorted based on the number of times mice licked during a bout. Averaged responses are shaded dark to light, scaling in order from 1 to 10 licks. Data were normalized by amplitude for each mouse in the data set $(n=7)$. On the right, peak fluorescence is plotted against number of licks in the bout. To illustrate that signals were not saturating across this range, the maximum peak amplitude for any $\mathrm{Ca}^{2+}$ response reached during sessions (i.e., $>10$ licks) is also shown. $\boldsymbol{B}$, Relationship between the slope of lick-induced $\mathrm{Ca}^{2+}$ responses and initial lick rate (measured at the third lick). Each dot represents an average of data (4-7 mice; in some cases mice did not have bouts containing the full repertoire of lick number variation). C, Trial-by-trial comparison of lick-induced Ca ${ }^{2+}$ responses measured in an MLI ensemble (black line; $4 \mu$ l aliquots) from a single mouse and the predicted response based on the underlying lick pattern for that trial (pink line). The asterisk denotes an instance where the evoked response was much larger than expected. D, Distribution of the SD of differences between measured and predicted Ca ${ }^{2+}$ activity evoked during cued bouts of licking (black). Responses outside an expected Gaussian distribution (gray) are highlighted in red. $\boldsymbol{E}$, Comparison of example MLI Ca ${ }^{2+}$ responses in a select trial $(n)$ and in the immediately preceding and following trials ( $n-1$ and $n+1$, respectively) for a series of lick bouts in a mouse. Summary plots show the average amplitude of evoked $\mathrm{Ca}^{2+}$ responses and the corresponding peak lick rates for those trials. The asterisk indicates significance $\left(t\right.$ test; $p=2.49 * 10{ }^{-6}$ and $1.96^{*} 10^{-5} ; n=7$ training sessions from 5 mice). Lick rate differences are not significant ( $t$ test; $p=0.77$ and 0.64$)$. $\boldsymbol{F}$, Immediately after probe trials where the lick port was moved unexpectedly before a cued bout of licking, the average amplitude of the $\mathrm{MLI} \mathrm{Ca}^{2+}$ response was no different than that in trials that preceded the perturbation $(t$ test; $p=0.53 ; n=7$ training sessions from 4 mice). G, Average instantaneous lick rates in trials immediately preceding and following a probe trial.

neered receptor (Armbruster et al., 2007) that can profoundly suppress MLI inhibition of Purkinje cells (S. Amat, M. Rowan, M. Gaffield, A. Bonnan, C. Kikuchi, H. Taniguchi, and J. Christie, unpublished observations). Following intraperitoneal administration of the cognate agonist $\mathrm{CNO}$, mean lick rate was significantly reduced in head restrained mice during ad libitum licking compared to control measurements in the same mice (Fig. $8 B$ ). $\mathrm{CNO}$ had no effect on lick rate in sham injected animals indicating the absence of off-target drug actions that could alter movement. To put the chemogenetic-induced effect on behavior in perspective, we plotted the distribution of lick rates used by these mice during ad libitum water consumption in control conditions providing an estimate of movement bandwidth (Fig. $8 C$ ). Suppression of MLI activity resulted in a $\sim 12 \%$ reduction in lick rate within this recorded range (Fig. $8 C$ ). High-speed videography recorded during these licks showed that the epoch of time with the mouth open during the consumption of water was significantly prolonged in the presence of $\mathrm{CNO}$ with little effect on the time with the mouth closed (Fig. 8D). A more detailed analysis of tongue movements during the mouth open period revealed a doubling of the variance in tongue position with MLI suppression (Fig. 8E), suggesting a more disorganized lick pattern. Similar to control conditions, we continued to observe accelerations in lick rate each time water was allocated despite the suppression of MLI activity, although we found a significant shift to lower mean rates across the entire patterned response (Fig. $8 F$ ).

Interestingly, on the first day of training, we observed that as mice learned to lick from the water port, their licking pattern 
A

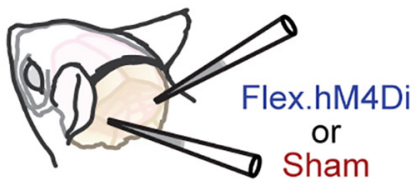

Left

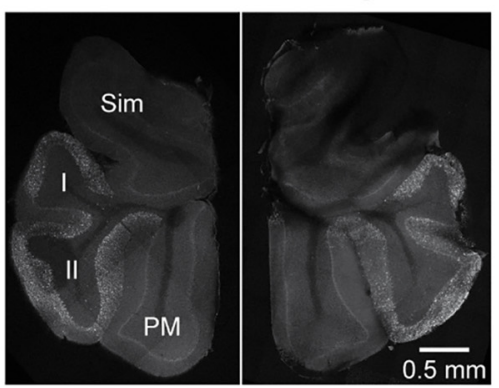

C

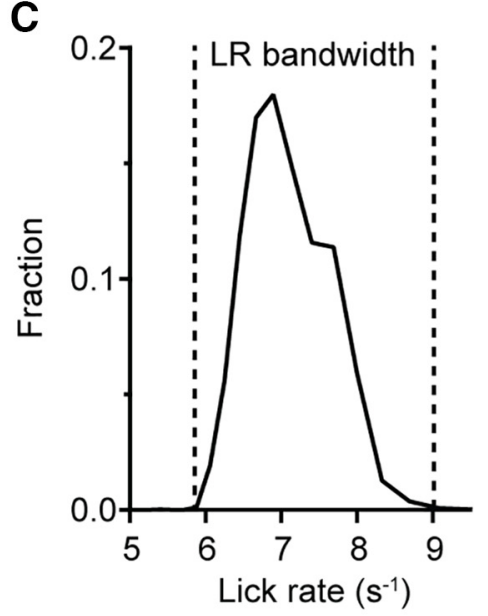

$\mathbf{F}$

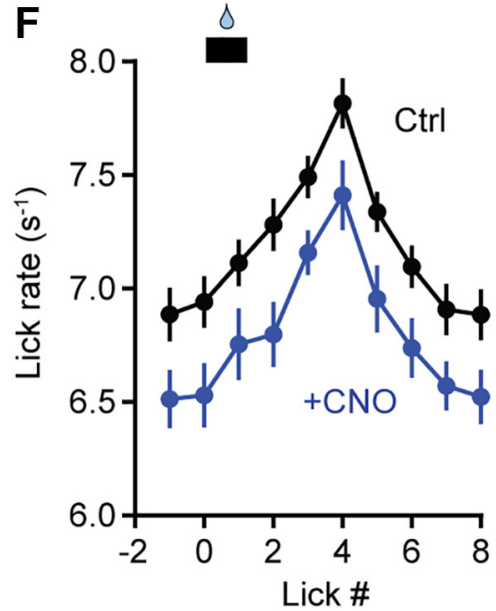

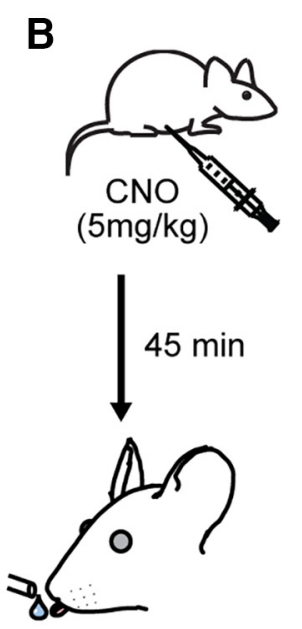

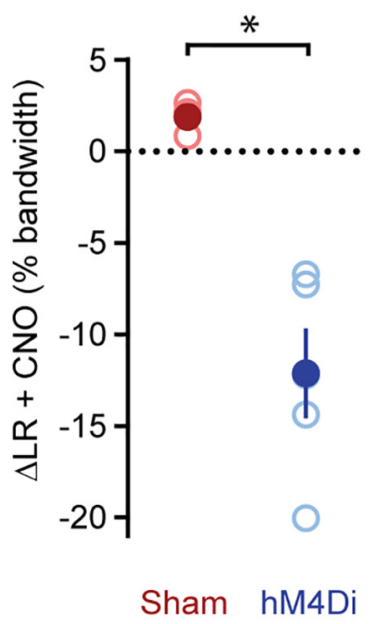

E
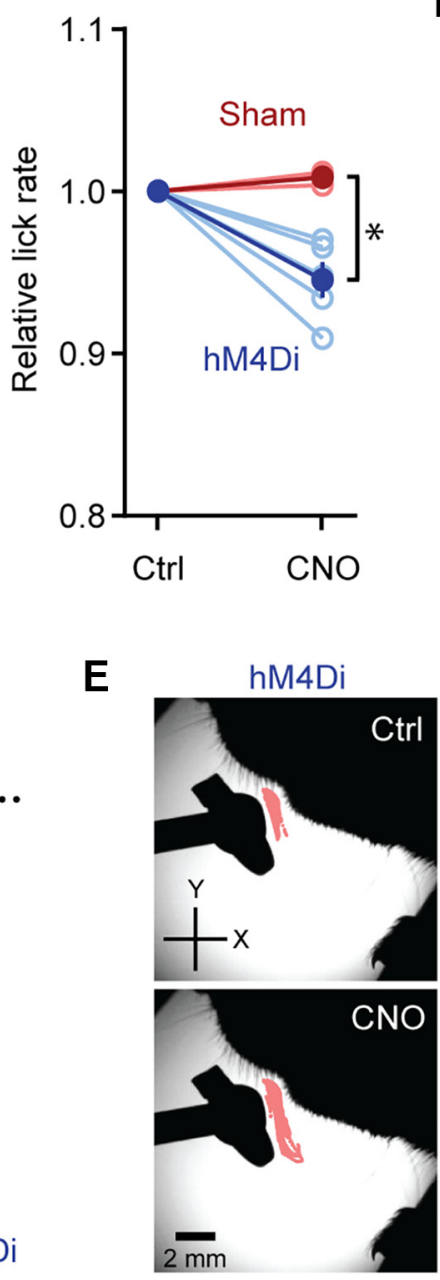

D

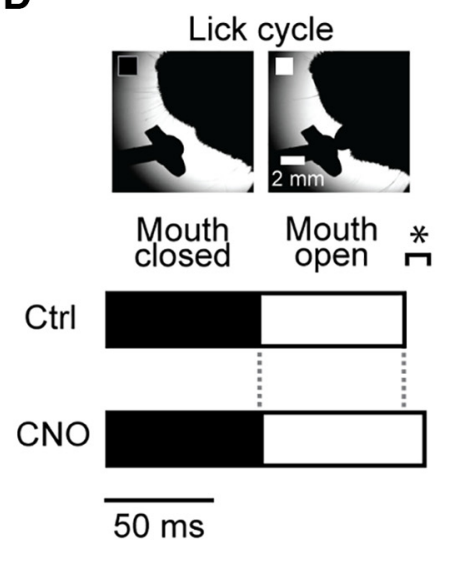

Tongue Position

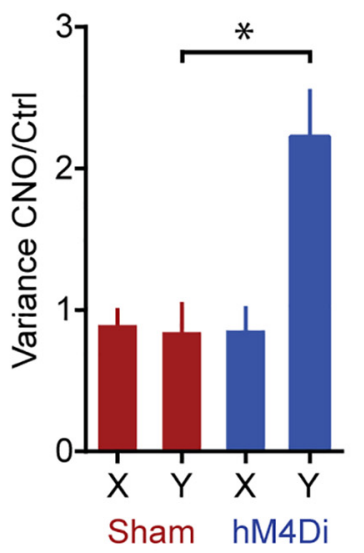

G

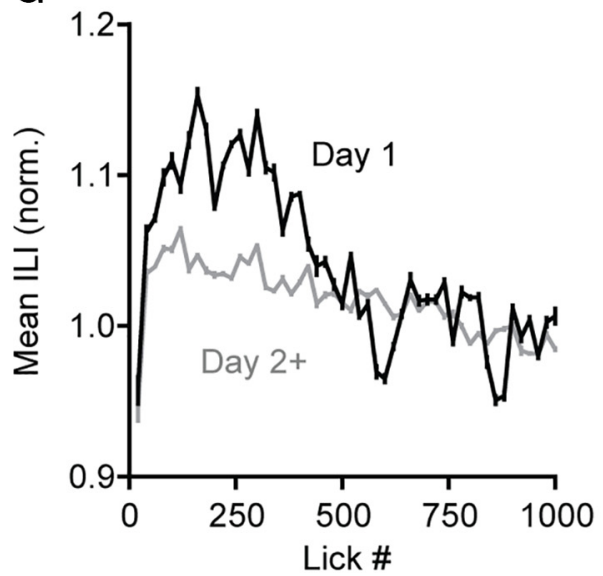

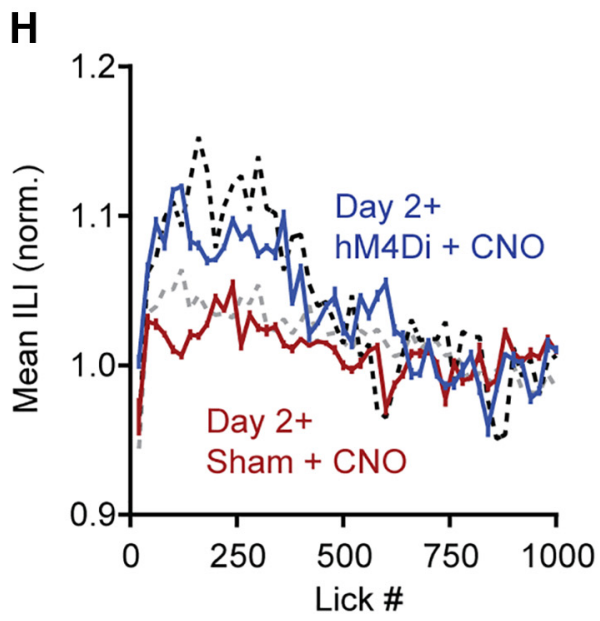

Figure 8. MLI activity contributes to the refinement of licking behavior. A, Either (re-dependent virus containing hM4Di or saline (sham) was injected into lobules Crus II of each cerebellar hemisphere of c-kit ${ }^{\text {RES-Cre }}$ mice. Representative images show the bilateral expression of hM4Di in the cerebellum of an injected animal. Sim, Simple lobule; I, Crus I; II, Crus II; PM, paramedian lobule. $B$, Diagram of the experimental protocol. For hM4Di- and sham-injected mice, CNO $(5 \mathrm{mg} / \mathrm{kg})$ was injected 45 min before commencement of the ad libitum licking task. In the plot, changes in lick rate are relative to control measurements (Ctrl) made during behavior without CNO injections (data points from each mouse are connected by lines). Dark colors are averages, and lighter colors are individual mice ( $n=3$ and 5 , sham and hM4Di mice, respectively; at least 2 sessions in each condition). The asterisk indicates significance ( $t$ test; $p=0.0038)$. C, Left, Histogram of the full lick rate bandwidth used in control conditions during ad libitum water consumption ( $n=6$ mice, $>4000$ licks). Right, The change in lick rate $(\Delta \mathrm{LR})$ with CNO as a percentage of the lick rate bandwidth for $\mathrm{hM} 4 \mathrm{Di}$ - and sham-injected animals. Dark colors are averages, and lighter colors are individual mice (sham, $1.8 \pm 0.5 \% ; \mathrm{hM} 4 \mathrm{Di},-12.1 \pm 2.5 \%)$. The asterisk indicates significance $(t$ test; $p=$ 0.0038). D, Example tongue images classified based on epochs with the mouth closed (left) or open (right) during licking. Bottom, Average time the mouth spent in the closed (black area) versus open (white area) state during the lick cycle for hM4Di-injected mice. Most of the difference between the control and CNO conditions occurred in the open state ( $n=3$ mice with at least 200 licks in each condition). The asterisk indicates significance ( $t$ test; $\left.p=4.7^{*} 10^{-17}\right)$. E, Example tongue centroid positions are shown in pink for a mouse injected with hM4Di in a control condition (top) and after CNO administration (bottom). The plot on the right shows the tongue centroid variance ratio between CNO and control conditions for both sham- (red) an (Figure legend continues.) 
changed with interlick intervals shifting to shorter durations with practice (Fig. $8 G$ ). Compared to the first day of training, licking was persistently faster on subsequent days of performance (Fig. $8 G$ ). We next investigated whether chemogenetic suppression of molecular layer inhibition affects this experience-dependent refinement of motor behavior. Strikingly, with MLI activity suppressed in experienced animals, there was a reversal to a lick pattern no different from that on the first day of training (Fig. $8 H$ ). CNO administration in sham injected, experienced animals had no effect (Fig. 8H). We conclude that MLIs not only encode kinematic information relating to movement rate, but, in mice trained to consume water from a lick port, their activity contributes to the optimization of motor output gained through experience.

\section{Discussion}

Two-photon imaging of movement-related $\mathrm{Ca}^{2+}$ activity in a densely labeled population of MLIs allowed us to measure how these neurons encode behaviorally relevant information pertaining to rhythmic motor control. During licking, we found coherent activity across an ensemble of MLIs contained within a specific lobule of the lateral cerebellum. The dominant source of information related to instantaneous lick rate without regard to tongue position, variation in sensory feedback, swallowing, or the unexpected perturbation of motor outcome. Chemogenetic suppression of molecular layer inhibition induced a reduction in lick rate and increased variability in tongue trajectories. Thus, MLIs not only encode kinematic variables describing temporal aspects of rhythmic movement, but also impose an effect on motor outcome. This indicates that these interneurons are involved in circuit computations important for online motor control during continuous movement.

\section{Encoding movement in MLI activity}

We found in lobule Crus II, a cerebellar region mapping the oral-facial extent (Shambes et al., 1978), that MLIs encode kinematic information describing the instantaneous lick rate. We found no evidence for the representation of tongue position, including lick trials where the tongue appeared to extend to its maximum extent. Therefore, positional information seems to not be a major component of the MLI Ca ${ }^{2+}$ response in this region of the cerebellum. However, we cannot exclude the possibility that positional information (or other types of sensorimotor information) is encoded with temporal dynamics too rapid for us to measure using fluorescence imaging of GECIs (Chen et al., 2013; Inoue et al., 2015). However, assuming the accuracy of our recording method in capturing the integrated neural response,

\footnotetext{
(Figure legend continued.) hM4Di-injected mice (blue). The same cohort of animals used in $D$ was used. ${ }^{*} p=0.033$ ( $t$ test $; n=3$ mice and 2 sessions for each condition). $\boldsymbol{F}$, Comparison of average lick rate in control and CNO conditions for 10 consecutive licks ( $n=5$ mice with at least two sessions for each condition). Water was dispensed at the time shown by the black bar. All licks except the lick at 1 showed a significant reduction in lick rate with CNO ( $t$ test; $p=0.01$ to 0.04). G, Plot of mean interlick interval (ILI) versus lick number for mice on the first day of training (Day 1, black line) and on subsequent days of training (Day $2+$, gray line). The two curves are significantly different (Kolmogorov-Smirnov test; $p=0.00097 ; n=6$ mice). $\boldsymbol{H}$, Similar to $\boldsymbol{G}$ with the addition of hM4Di- and sham-injected animals (blue and red lines, respectively) after CNO administration ( $n=3$ mice and 2 sessions for each condition). CNO induced a significant effect in experienced mice expressing hM4Di. Licking patterns were comparable to animals on their first day of training (black dashed line; Kolmogorov-Smirnov test; $p=0.36$ ) and different from both sham-injected mice and mice that received previous training (gray dashed line; Kolmogorov-Smirnov test; $p=7.2 * 10^{-6}$ and 0.0021 , respectively).
}

this would suggest a bias toward rate-based activity coding that is likely necessary for temporal coordination of regular, continuous movement (Heck et al., 2013), motor behavior that benefits from accurate absolute timing rather than features attuned to articulation in space. Previous reports indicate that Purkinje cells modulate their spiking in coordination with licking in the lateral cerebellar hemispheres including both Crus I and II (Bryant et al., 2010). Bryant et al. (2010) recorded from a small collection of cells residing within a region similar to our craniotomy location and observed lick-related spike modulation in both lobules, in contrast to our findings. Certainly, we cannot rule out the possibility that some MLIs in Crus I were encoding lick-related activity but were outside of our imaging window. However, if coding differences do exist between Purkinje cells and MLIs in Crus I, it may reflect that these two cell types are excited in a time-varying manner by distinct groups of parallel fibers (Jörntell and Ekerot, 2002) or that Purkinje cell spiking is differentially influenced by the composite balance of molecular layer excitation and inhibition dependent on differences in synaptic or intrinsic properties between cell types (Gao et al., 2012).

In our recordings, MLI activation preceded the initiation of any visible movement. This result is consistent with a predominant role for coding efferent (motor) information emanating from either the motor cortex or brainstem because sensory information is expected to be delayed relative to execution of movement itself. However, provided the temporal limits of our technique and the inability to fully resolve the entire trajectory of the tongue, it is possible that MLIs are also (or instead) encoding proprioceptive signals relating to licking movements. Further experimentation will be required to fully parse these possibilities. Nevertheless, we found no evidence for the overt representation of sensory information in the MLI $\mathrm{Ca}^{2+}$ response reporting, for example, lick port contact or task specific variables that led to adjustment of instantaneous lick rate. It may be that predictable features of sensory input are normally canceled during movement and are not apparent in the activity of MLIs (Ozden et al., 2012). Yet even after inducing deviations in sensorimotor expectations in an attempt to create sensory prediction errors that report differences between intended and actual motor outcomes (Bastian, 2006; Sawtell, 2017), we observed no additional information content in the MLI response. Sensory prediction errors are thought to be conveyed by climbing fibers whose firing also synchronizes during movement, including licking (Welsh et al., 1995). MLIs are excited by climbing fibers through extrasynaptic signaling (Jörntell and Ekerot, 2003; Szapiro and Barbour, 2007), and could contribute to coherent MLI activity, possibly through plasticity mechanisms, although it is unknown if climbing fiber firing is sufficient to drive $\mathrm{Ca}^{2+}$ activity in MLIs (Mathews et al., 2012; Coddington et al., 2013) as in Purkinje cells.

The representation of lick rate was reliable in the MLI ensemble from trial to trial. However, some variability outside of the expected range occurred within a subset of trials. We cannot eliminate the possibility that unaccounted sources of motor or sensory information drove the additional $\mathrm{Ca}^{2+}$ component in these trials. It also remains possible the MLI $\mathrm{Ca}^{2+}$ activity is regulated by neuromodulatory inputs into the cerebellum (Schweighofer et al., 2004; Guo et al., 2016), whose activity has been shown to vary with brain state such as alertness or the anticipation of reward (Lee and Dan, 2012), a feature that may be encoded by granule cells (Wagner et al., 2017). Alternatively, noise in the MLI response could improve information transfer to Purkinje cells (Buchin et al., 2016) or get filtered out (Porrill et al., 2013) and therefore not result in movement alterations. 


\section{Organization of MLI activity}

During movement, we observed a broad zone of MLI excitation without indication of climbing fiber delimited banding as apparent in Purkinje cell $\mathrm{Ca}^{2+}$ activity in the same region (Tsutsumi et al., 2015; Gaffield et al., 2016). On average, MLIs responded in concert with similar levels of activity, indicating the absence of specialization within their population. Although, the lack of movement-related banding patterns does not rule out the possibility of a more complex MLI organization that may be revealed under different behavior conditions. In contrast, Purkinje cells can differentially modulate their activity during movement (Raymond and Lisberger, 1997; Medina and Lisberger, 2008; Jelitai et al., 2016), either by increasing or decreasing their firing rate (bursting or pause cells). This suggests a greater amount of diversity in the Purkinje cell ensemble compared to their MLI inputs. Coherent MLI activity may well drive wide-ranging responses in the heterogeneous Purkinje cell population.

Granule cells drive large unitary excitatory potentials in MLIs resulting in strong coupling between synaptic input and spiking (Carter and Regehr, 2002; Jörntell and Ekerot, 2003). Therefore, the pervasive movement-related $\mathrm{Ca}^{2+}$ response in MLIs almost certainly emanates from granule cells possibly driving correlated excitation of MLIs by their collective activity across multiple parallel fiber beams. Electrical junctions between MLIs promote rapid synchrony and further propagate granule cell-mediated excitation to neighboring MLIs (Mann-Metzer and Yarom, 1999; Kim et al., 2014; Rieubland et al., 2014), resulting in global inhibition within the molecular layer.

\section{Functional influence of MLI activity on motor output}

By providing inhibitory drive onto Purkinje cells, MLIs are poised to play an important role in information processing during movement. However, Purkinje cells can linearly rate code granule cell excitation independent of inhibition, albeit with a loss in spike precision (Walter and Khodakhah, 2006, 2009). Such coding regimes allow for accurate representation of movement kinematics (Chen et al., 2016). This suggests that the cerebellum can execute algorithmic computation of motor action independent of MLI activity. It follows that genetic ablation of $\mathrm{GABA}_{\mathrm{A}}$ receptors from Purkinje cells does not result in gross motor disruption (although licking was not examined; Wulff et al., 2009). However, we found direct evidence that the activity of MLIs modifies motor control, affecting the rate and consistency of continuous movement. This implicates molecular layer inhibition as a key component of circuit-level processing that imposes an online influence on motor behavior. It is important to note that this influence may not depend on the type of information (motor command or proprioceptive feedback) transmitted through the MLIs. Any disruption of MLI to Purkinje cell signaling could act to suppress motor activity either by decreasing overall cerebellar output or by disrupting Purkinje cell firing patterns required to properly modulate cortical motor commands.

The consumption of water involves a number of rhythmic motor actions including articulation of the jaw and tongue while coordinating with motor centers controlling swallowing and breathing (Moore et al., 2013, 2014). Coordination of such regular, stereotyped movements will likely depend on the accurate temporal processing of continuous motion. Disruption of MLIs in the lateral cerebellum lowered overall lick rate to levels observed after blocking total cerebellar output (Bryant et al., 2010), suggesting MLI activity contributes greatly to the cerebellum's role in organizing licking. Although licking is an innate behavior in mice, it is likely that consuming water from a port during head-fixation requires practice and benefits from motor learning. Of note, nearly all of our measurements were obtained from animals trained to consume from a port and that repeatedly performed the movement task before neural activity measurements and perturbations. MLIs are subject to plasticity (Liu and Cull-Candy, 2000; Soler-Llavina and Sabatini, 2006) and have been implicated in the expression of motor learning by driving timed pauses in Purkinje cell spiking (Wulff et al., 2009; ten Brinke et al., 2015). Additional study will be necessary to determine how MLI-dependent plasticity may alter activity patterns in the cerebellar cortex that are involved in the expression of motor learning, processes that might help shape motor performance in our behavior paradigm.

\section{References}

Armbruster BN, Li X, Pausch MH, Herlitze S, Roth BL (2007) Evolving the lock to fit the key to create a family of $\mathrm{G}$ protein-coupled receptors potently activated by an inert ligand. Proc Natl Acad Sci U S A 104:51635168. CrossRef Medline

Barmack NH, Yakhnitsa V (2008) Functions of interneurons in mouse cerebellum. J Neurosci 28:1140-1152. CrossRef Medline

Bastian AJ (2006) Learning to predict the future: the cerebellum adapts feedforward movement control. Curr Opin Neurobiol 16:645-649. CrossRef Medline

Bryant JL, Boughter JD, Gong S, LeDoux MS, Heck DH (2010) Cerebellar cortical output encodes temporal aspects of rhythmic licking movements and is necessary for normal licking frequency. Eur J Neurosci 32:41-52. CrossRef Medline

Buchin A, Rieubland S, Häusser M, Gutkin BS, Roth A (2016) Inverse stochastic resonance in cerebellar Purkinje cells. PLoS Comput Biol 12: e1005000. CrossRef Medline

Carter AG, Regehr WG (2002) Quantal events shape cerebellar interneuron firing. Nat Neurosci 5:1309-1318. CrossRef Medline

Chen S, Augustine GJ, Chadderton P (2016) The cerebellum linearly encodes whisker position during voluntary movement. Elife 5:e10509. Medline

Chen TW, Wardill TJ, Sun Y, Pulver SR, Renninger SL, Baohan A, Schreiter ER, Kerr RA, Orger MB, Jayaraman V, Looger LL, Svoboda K, Kim DS (2013) Ultrasensitive fluorescent proteins for imaging neuronal activity. Nature 499:295-300. CrossRef Medline

Coddington LT, Rudolph S, Vande Lune P, Overstreet-Wadiche L, Wadiche JI (2013) Spillover-mediated feedforward inhibition functionally segregates interneuron activity. Neuron 78:1050-1062. CrossRef Medline

Dizon MJ, Khodakhah K (2011) The role of interneurons in shaping Purkinje cell responses in the cerebellar cortex. J Neurosci 31:10463-10473. CrossRef Medline

Eccles JC, Ito M, Szentágothai J (1967) The cerebellum as a neuronal machine. New York: Springer.

Ekerot CF, Jörntell H (2001) Parallel fibre receptive fields of Purkinje cells and interneurons are climbing fibre-specific. Eur J Neurosci 13:13031310. CrossRef Medline

Gaffield MA, Amat SB, Bito H, Christie JM (2016) Chronic imaging of movement-related Purkinje cell calcium activity in awake behaving mice. J Neurophysiol 115:413-422. CrossRef Medline

Gao Z, van Beugen BJ, De Zeeuw CI (2012) Distributed synergistic plasticity and cerebellar learning. Nat Rev Neurosci 13:619-635. CrossRef Medline

Guo A, Feng JY, Li J, Ding N, Li YJ, Qiu DL, Piao RL, Chu CP (2016) Effects of norepinephrine on spontaneous firing activity of cerebellar Purkinje cells in vivo in mice. Neurosci Lett 629:262-266. CrossRef Medline

Heck DH, De Zeeuw CI, Jaeger D, Khodakhah K, Person AL (2013) The neuronal code(s) of the cerebellum. J Neurosci 33:17603-17609. CrossRef Medline

Heiney SA, Kim J, Augustine GJ, Medina JF (2014) Precise control of movement kinematics by optogenetic inhibition of Purkinje cell activity. J Neurosci 34:2321-2330. CrossRef Medline

Holtmaat A, Bonhoeffer T, Chow DK, Chuckowree J, De Paola V, Hofer SB, Hübener M, Keck T, Knott G, Lee WC, Mostany R, Mrsic-Flogel TD, Nedivi E, Portera-Cailliau C, Svoboda K, Trachtenberg JT, Wilbrecht L (2009) Long-term, high-resolution imaging in the mouse neocortex through a chronic cranial window. Nat Protoc 4:1128-1144. CrossRef Medline 
Inoue $\mathrm{M}$, Takeuchi A, Horigane S, Ohkura M, Gengyo-Ando K, Fujii H, Kamijo S, Takemoto-Kimura S, Kano M, Nakai J, Kitamura K, Bito H (2015) Rational design of a high-affinity, fast, red calcium indicator R-CaMP2. Nat Methods 12:64-70. Medline

Ito M (2012) Cerebellum: The brain for implicit self. Upper Saddle River, NJ: FT.

Jelitai M, Puggioni P, Ishikawa T, Rinaldi A, Duguid I (2016) Dendritic excitation-inhibition balance shapes cerebellar output during motor behaviour. Nat Commun 7:13722. CrossRef Medline

Jörntell H, Ekerot CF (2002) Reciprocal bidirectional plasticity of parallel fiber receptive fields in cerebellar Purkinje cells and their afferent interneurons. Neuron 34:797-806. CrossRef Medline

Jörntell H, Ekerot CF (2003) Receptive field plasticity profoundly alters the cutaneous parallel fiber synaptic input to cerebellar interneurons in vivo. J Neurosci 23:9620-9631. Medline

Khilkevich A, Halverson HE, Canton-Josh JE, Mauk MD (2016) Links between single-trial changes and learning rate in eyelid conditioning. Cerebellum 15:112-121. CrossRef Medline

Kim J, Lee S, Tsuda S, Zhang X, Asrican B, Gloss B, Feng G, Augustine GJ (2014) Optogenetic mapping of cerebellar inhibitory circuitry reveals spatially biased coordination of interneurons via electrical synapses. Cell Rep 7:1601-1613. CrossRef Medline

Lee KH, Mathews PJ, Reeves AM, Choe KY, Jami SA, Serrano RE, Otis TS (2015) Circuit mechanisms underlying motor memory formation in the cerebellum. Neuron 86:529-540. CrossRef Medline

Lee SH, Dan Y (2012) Neuromodulation of brain states. Neuron 76:209222. CrossRef Medline

Lisberger SG, Fuchs AF (1978) Role of primate flocculus during rapid behavioral modification of vestibuloocular reflex. I. Purkinje cell activity during visually guided horizontal smooth-pursuit eye movements and passive head rotation. J Neurophysiol 41:733-763. Medline

Liu SQ, Cull-Candy SG (2000) Synaptic activity at calcium-permeable AMPA receptors induces a switch in receptor subtype. Nature 405:454458. CrossRef Medline

Mann-Metzer P, Yarom Y (1999) Electrotonic coupling interacts with intrinsic properties to generate synchronized activity in cerebellar networks of inhibitory interneurons. J Neurosci 19:3298-3306. Medline

Mathews PJ, Lee KH, Peng Z, Houser CR, Otis TS (2012) Effects of climbing fiber driven inhibition on Purkinje neuron spiking. J Neurosci 32:1798817997. CrossRef Medline

Medina JF (2011) The multiple roles of Purkinje cells in sensori-motor calibration: to predict, teach and command. Curr Opin Neurobiol 21: 616-622. CrossRef Medline

Medina JF, Lisberger SG (2008) Links from complex spikes to local plasticity and motor learning in the cerebellum of awake-behaving monkeys. Nat Neurosci 11:1185-1192. CrossRef Medline

Mittmann W, Koch U, Häusser M (2005) Feed-forward inhibition shapes the spike output of cerebellar Purkinje cells. J Physiol 563:369-378. CrossRef Medline

Moore JD, Deschênes M, Furuta T, Huber D, Smear MC, Demers M, Kleinfeld D (2013) Hierarchy of orofacial rhythms revealed through whisking and breathing. Nature 497:205-210. CrossRef Medline

Moore JD, Kleinfeld D, Wang F (2014) How the brainstem controls orofacial behaviors comprised of rhythmic actions. Trends Neurosci 37:370380. CrossRef Medline

Ozden I, Dombeck DA, Hoogland TM, Tank DW, Wang SS (2012) Widespread state-dependent shifts in cerebellar activity in locomoting mice. PLoS One 7:e42650. CrossRef Medline

Porrill J, Dean P, Anderson SR (2013) Adaptive filters and internal models: multilevel description of cerebellar function. Neural Netw 47:134-149. CrossRef Medline
Raymond JL, Lisberger SG (1997) Multiple subclasses of Purkinje cells in the primate floccular complex provide similar signals to guide learning in the vestibulo-ocular reflex. Learn Mem 3:503-518. CrossRef Medline

Rieubland S, Roth A, Häusser M (2014) Structured connectivity in cerebellar inhibitory networks. Neuron 81:913-929. CrossRef Medline

Sawtell NB (2017) Neural mechanisms for predicting the sensory consequences of behavior: insights from electrosensory systems. Annu Rev Physiol 79:381-399. Medline

Scelfo B, Sacchetti B, Strata P (2008) Learning-related long-term potentiation of inhibitory synapses in the cerebellar cortex. Proc Natl Acad Sci U S A 105:769-774. CrossRef Medline

Schweighofer N, Doya K, Kuroda S (2004) Cerebellar aminergic neuromodulation: towards a functional understanding. Brain Res Brain Res Rev 44:103-116. CrossRef Medline

Shambes GM, Gibson JM, Welker W (1978) Fractured somatotopy in granule cell tactile areas of rat cerebellar hemispheres revealed by micromapping. Brain Behav Evol 15:94-140. Medline

Slotnick B (2009) A simple 2-transistor touch or lick detector circuit. J Exp Anal Behav 91:253-255. CrossRef Medline

Soler-Llavina GJ, Sabatini BL (2006) Synapse-specific plasticity and compartmentalized signaling in cerebellar stellate cells. Nat Neurosci 9:798 806. CrossRef Medline

Szapiro G, Barbour B (2007) Multiple climbing fibers signal to molecular layer interneurons exclusively via glutamate spillover. Nat Neurosci 10: 735-742. CrossRef Medline

ten Brinke MM, Boele HJ, Spanke JK, Potters JW, Kornysheva K, Wulff P, IJpelaar AC, Koekkoek SK, De Zeeuw CI (2015) Evolving models of pavlovian conditioning: cerebellar cortical dynamics in awake behaving mice. Cell Rep 13:1977-1988. CrossRef Medline

Thach WT (1968) Discharge of Purkinje and cerebellar nuclear neurons during rapidly alternating arm movements in the monkey. J Neurophysiol 31:785797. Medline

Tsutsumi S, Yamazaki M, Miyazaki T, Watanabe M, Sakimura K, Kano M, Kitamura K (2015) Structure-function relationships between aldolase $\mathrm{C} /$ zebrin II expression and complex spike synchrony in the cerebellum. J Neurosci 35:843-852. CrossRef Medline

Wagner MJ, Kim TH, Savall J, Schnitzer MJ, Luo L (2017) Cerebellar granule cells encode the expectation of reward. Nature.

Walter JT, Khodakhah K (2006) The linear computational algorithm of cerebellar Purkinje cells. J Neurosci 26:12861-12872. CrossRef Medline

Walter JT, Khodakhah K (2009) The advantages of linear information processing for cerebellar computation. Proc Natl Acad Sci U S A 106:44714476. CrossRef Medline

Walter JT, Dizon MJ, Khodakhah K (2009) The functional equivalence of ascending and parallel fiber inputs in cerebellar computation. J Neurosci 29:8462-8473. CrossRef Medline

Welsh JP, Lang EJ, Suglhara I, Llinás R (1995) Dynamic organization of motor control within the olivocerebellar system. Nature 374:453-457. CrossRef Medline

Wolpert DM, Miall RC (1996) Forward models for physiological motor control. Neural Netw 9:1265-1279. CrossRef Medline

Wulff P, Schonewille M, Renzi M, Viltono L, Sassoè-Pognetto M, Badura A, Gao Z, Hoebeek FE, van Dorp S, Wisden W, Farrant M, De Zeeuw CI (2009) Synaptic inhibition of Purkinje cells mediates consolidation of vestibulocerebellar motor learning. Nat Neurosci 12:1042-1049. CrossRef Medline

Yang Y, Lisberger SG (2014a) Purkinje-cell plasticity and cerebellar motor learning are graded by complex-spike duration. Nature 510:529-532. CrossRef Medline

Yang Y, Lisberger SG (2014b) Role of plasticity at different sites across the time course of cerebellar motor learning. J Neurosci 34:7077-7090. CrossRef Medline 